\title{
Gut microbiota in patients with Alzheimer's disease spectrum: a systematic review and meta-analysis
}

\author{
Chun-Che Hung ${ }^{1,2}$, Chiung-Chih Chang $^{3}$, Chi-Wei Huang $^{3}$, Rui Nouchi ${ }^{4,5}$, Chia-Hsiung Cheng ${ }^{1,2,6,7}$ \\ ${ }^{1}$ Department of Occupational Therapy and Graduate Institute of Behavioral Sciences, Chang Gung University, \\ Taoyuan, Taiwan \\ ${ }^{2}$ Laboratory of Brain Imaging and Neural Dynamics (BIND Lab), Chang Gung University, Taoyuan, Taiwan \\ ${ }^{3}$ Department of Neurology and Institute for Translational Research in Biomedicine, Kaohsiung Chang Gung \\ Memorial Hospital, Chang Gung University College of Medicine, Kaohsiung, Taiwan \\ ${ }^{4}$ Department of Cognitive Health Science, Institute of Development, Aging and Cancer (IDAC), Tohoku University, \\ Sendai, Japan \\ ${ }^{5}$ Smart Aging Research Center (S.A.R.C), Tohoku University, Sendai, Japan \\ ${ }^{6}$ Healthy Aging Research Center, Chang Gung University, Taoyuan, Taiwan \\ ${ }^{7}$ Department of Psychiatry, Chang Gung Memorial Hospital, Linkou, Taiwan \\ Correspondence to: Chia-Hsiung Cheng, Rui Nouchi; email: ch.cheng@mail.cgu.edu.tw, rui.nouchi.a4@tohoku.ac.jp \\ Keywords: Alzheimer's disease, mild cognitive impairment, gut microbiota, dysbiosis, systematic review, meta-analysis \\ Received: August 27, $2021 \quad$ Accepted: December 20, $2021 \quad$ Published: January 14, 2022
}

Copyright: (C) 2022 Hung et al. This is an open access article distributed under the terms of the Creative Commons Attribution License (CC BY 3.0), which permits unrestricted use, distribution, and reproduction in any medium, provided the original author and source are credited.

\section{ABSTRACT}

Context: Gut dysbiosis has been proposed as one of pathologies in patients with Alzheimer's disease (AD) spectrum. Despite such enthusiasm, the relevant results remain substantially controversial.

Objective: A systematic review and meta-analysis were performed to investigate the differences of gut microbiota (GM) between patients with $A D$ spectrum (including mild cognitive impairment $[\mathrm{MCl}]$ and $A D$ ) and healthy controls (HC).

Data sources: PubMed, MEDLINE, Scopus, and Cochrane Library from January 2000 to August 2021.

Eligibility criteria for study selection: Observational trials and pre-intervention data of intervention trials that investigated the abundance of GM in patients with AD spectrum and HC.

Data extraction and synthesis: Two reviewers independently identified articles, extracted data, and evaluated the risk of bias. The effect sizes were performed by a random-effect, inverse-variance weighted model. The effects of different countries and of clinical stages on GM abundance were also examined.

Results: 11 studies consisting of $378 \mathrm{HC}$ and 427 patients with AD spectrum were included in the meta-analysis. Patients with $A D$, but not $\mathrm{MCl}$, showed significantly reduced $\mathrm{GM}$ diversity as compared to $\mathrm{HC}$. We also found more abundance of Proteobacteria, Bifidobacterium and Phascolarctobacterium, but less abundance of Firmicutes, Clostridiaceae, Lachnospiraceae and Rikenellaceae in patients with AD spectrum as compared with HC. The profiles of abundance of Alistipes and Bacteroides in HC and AD spectrum were differentially affected by countries. Finally, when considering clinical stage as a moderator, the comparisons of abundance in Clostridiaceae and Phascolarctobacterium showed large effect sizes, with gradient changes from MCI to AD stage.

Limitations: The inclusion of studies originating only from China and the U.S. was a possible limitation. Conclusions: Patients with AD spectrum demonstrated altered GM abundance, which was differentially mediated by countries and clinical stages. 


\section{INTRODUCTION}

Previous studies have suggested that amyloid-beta $(A \beta)$ peptide deposition in the brain is an early neural change in patients with Alzheimer's disease (AD) [1, 2]. However, the etiopathogenesis of AD are not well explained. Recent evidence has focused on a potential role of gut microbiota (GM) in the development or exacerbation of $\mathrm{AD}[3-5]$.

There are thousands of microbes residing in the human gut, which involves crucial functions for individual physiology and development [6]. Moreover, accumulating evidence has revealed that the gut and central nervous system (CNS) interact with one another through the following neuro-chemical pathways. First, GM may produce and release neurotransmitters and neurotoxins such as short-chain fatty acids (SCFAs), 5HT, acetylcholine, tryptophan, and D-lactate and ammonia [7-9]. All these molecules are transmitted by the systemic circulation and then cross the blood-brain barrier (BBB) to modulate neural activities. Second, connections of enteric nervous system (ENS) and CNS is through the vagus nerve and the autonomic nervous system [10]. Upon activation of ENS, it receives signals from GM, and then affects the gut cells and regulates anti-inflammatory effects of the peripheral immune system $[11,12]$. Finally, GM is involved in the modulation of immune system through the synthesis and release of pro-inflammatory cytokines such as interleukin-1, interleukin-6 and tumor necrosis factor-alpha [13, 14]. Interestingly, previous studies have found that GM affects the host's maturation of the neuroendocrine, nervous, and immune system; hence, the gut-brain axis plays an important role in the bidirectional communications between the ENS and CNS [15-17]. Notably, compelling evidence has proposed that any disturbance in these routes would potentially be associated with the $\mathrm{AD}$ occurrence $[18,19]$.

More recently, the changes in diversity and equilibrium of GM have attracted much attention in many neurological and psychiatric disorders. When the intestinal ecosystem is abnormally altered, the composition of GM becomes imbalanced (i.e., dysbiosis). This dysbiotic pattern prompts the host to establish a disease-related microbial community, leading to leaky intestine and BBB, as well as bacterial translocation [20]. Animal studies have demonstrated that gut dysbiosis is involved in the pathogenesis of $\mathrm{AD}$ $[21,22]$. Studies from clinical settings have also explored the composition of GM in the patients with AD spectrum, including mild cognitive impairment (MCI) and AD [23-28]. Several GM strains were reported to be associated with the cognitive functions and neuropsychiatric symptoms in patients with $\mathrm{AD}$ [29]. Furthermore, it has been suggested that probiotics supplementation may be an effective dietary intervention for individuals with $\mathrm{AD}[30,31]$ and other conditions, such as polycystic ovarian syndrome [32] and major depressive disorder [33].

It is interesting to note that the composition of GM is distinct from country to country. For instance, a previous study from U.S. showed an alteration of GM in patients with $\mathrm{AD}$, comprising increased Bacteroidetes and reduced Actinobacteria in the phylum level [26]. In contrast, Zhuang and colleagues demonstrated opposite results in Chinese patients with $\mathrm{AD}$ (i.e., reduced Bacteroidetes and increased Actinobacteria) [27]. In addition, the magnitudes of gut dysbiosis have been reported to be different between patients with MCI and $\mathrm{AD}$. Most of the existing literature revealed that patients with $\mathrm{AD}$, but not $\mathrm{MCI}$, demonstrated significantly reduced GM diversity compared to healthy older adults $[25,26,29]$. However, there was a study reporting similar GM diversity and abundance in patients with MCI and AD [24]. Thus, it remains unclear whether different clinical stages lead to different magnitudes of gut dysbiosis.

To the best of our knowledge, no statistical review of GM structure in patients with $\mathrm{AD}$ spectrum has been performed. Therefore, the purpose of this study was two-fold. First, we aimed to determine the differences of GM diversity and abundance between the patients with AD spectrum and healthy controls (HC). Second, we further examined the potential effects of different countries and clinical stages on GM abundance.

\section{METHODS}

\section{Literature search}

This meta-analysis followed the Preferred Reporting Items for Systematic reviews and Meta-Analyses (PRISMA) guidelines [34]. We conducted a comprehensive literature search in PubMed, MEDLINE, Scopus, and Cochrane Library electronic databases from January 2000 to August 2021, with combinations of the following terms: ("Alzheimer's disease" OR "dementia" OR "mild cognitive impairment" OR "cognitive dysfunction") AND ("microbiota" OR "gut microbiota" OR "microbiome"). Moreover, the reference lists of the selected articles or reviews were also included as additional studies.

\section{Eligibility criteria}

Two authors ( $\mathrm{CCH}$ and $\mathrm{CHC})$ independently screened and identified the full texts that met the following 
inclusion criteria: (1) they were peer-reviewed articles written in English; (2) GM diversity and abundance was compared between patients with $\mathrm{AD}$ spectrum and $\mathrm{HC}$; (3) GM was derived from stool samples; (4) only preintervention data were collected from the intervention studies; (5) the GM strains were investigated by at least three studies; (6) adequate statistical data (e.g., mean, standard deviation, $p$ values, median, maximum, minimum, etc.) to estimate effect sizes. Studies of case reports, systematic reviews and animal research were excluded.

\section{Outcome measures}

The primary outcomes consisted of GM diversity (including $\alpha$ diversity and $\beta$ diversity) and differences of GM abundance between the patients with $\mathrm{AD}$ spectrum and HC. The secondary outcomes consisted of the effects of different countries and clinical stages on GM abundance.

\section{Data extraction}

The necessary data of each study regarding the number of participants, age, body mass index, diabetes mellitus, dietary assessments, diversity and abundance of GM, etc. were extracted by $\mathrm{CCH}$ and checked by $\mathrm{CHC}$. Median, minimum, maximum, or $95 \%$ confidence interval (CI) from 5 studies were estimated from the bar graphs [25-28, 35]. Discrepancies with study criteria or data coding were resolved by debate and consensus.

\section{Risk of bias assessment}

Two authors ( $\mathrm{CCH}$ and $\mathrm{CHC})$ independently assessed the risk of bias in each included study using the Risk of Bias Assessment Tool for Nonrandomized Studies (RoBANS) [36], which evaluates six possible sources of bias: selection of participants, confounding variables, measurement of exposure, blinding of outcome assessments, incomplete outcome data, and selective outcome reporting. Disagreements were resolved by consensus or by consultation with a third author.

\section{Effect size calculations}

The Comprehensive Meta-Analysis Version 3 software (Biostat Inc., Englewood, NJ, USA) was applied to calculate the effect sizes with a random-effect, inversevariance weighted model. Postulating that departures from Gaussian distributions were not serious, we used previously reported conversion equations [37] to estimate means and standard deviation from median, maximum and minimum. Hedges' $g$ effect sizes were derived from the mean differences between groups of $\mathrm{AD}$ spectrum and $\mathrm{HC}$, divided by the pooled standard deviation of these groups. Heterogeneity across each study was evaluated using Q-statistic and $\mathrm{I}^{2}$. Additionally, the inclusion of outliers may result in bias and significantly influence the pooled effect sizes [38, 39]. We defined the outliers with the following criteria: 1) for which the upper boundary of the $95 \% \mathrm{CI}$ is lower than the lower boundary of the overall effect CI (i.e., extremely small effect sizes); (2) for which the lower boundary of the $95 \% \mathrm{CI}$ is higher than the upper boundary of the overall effect CI (i.e., extremely large effect sizes).

Potential publication bias of each GM abundance was quantitatively assessed by Begg and Mazumdar rank correlation [40] and Egger's regression intercept tests [41]. Moreover, the Duval and Tweedie's trim and fill method was used to correct for non-normal distribution of effect sizes potentially due to the file drawer problem. The significant levels were set at $p<0.05$.

\section{Availability of data}

Data available on request from the corresponding authors.

\section{RESULTS}

\section{Study selection and characteristics}

By the comprehensive literature search, 164 relevant articles were yielded when duplications were excluded. After the review of the titles and abstracts, 14 studies were potentially eligible for our meta-analysis. After carefully examining the full texts, three additional studies were removed: two did not provide sufficient data [42, 43] and one did not report common GM strains as other studies [44]. Therefore, the remaining 11 articles were included in the final meta-analysis (Figure 1). Table 1 summarizes the clinical and demographic characteristics of the 11 studies. These studies were performed in China [23-25, 27, 29, 35, 45, 46] and U.S. [26, 28, 47], with a total of $378 \mathrm{HC}$ and 427 patients with $\mathrm{AD}$ spectrum $(\mathrm{AD}=251, \mathrm{MCI}=124$, $\mathrm{aMCI}=52$ ).

\section{Primary outcomes: $\alpha$ diversity and $\beta$ diversity}

Among the indices of $\alpha$ diversity, Shannon index and Simpson index were most frequently measured in our included articles. There were no significant differences of $\alpha$ diversity between $\mathrm{HC}$ and $\mathrm{AD}$ spectrum (Figure 2). However, when patients with AD spectrum were divided into those with $\mathrm{MCI}$ and $\mathrm{AD}$, the results showed that $\mathrm{AD}$ but not $\mathrm{MCI}$ demonstrated significantly reduced $\alpha$ diversity as indexed by Shannon index (Hedges' $\mathrm{g}=0.237 ; 95 \% \mathrm{CI}=0.023$ to 0.451 ; 
Table 1. Characteristics of each study included in the meta-analysis.

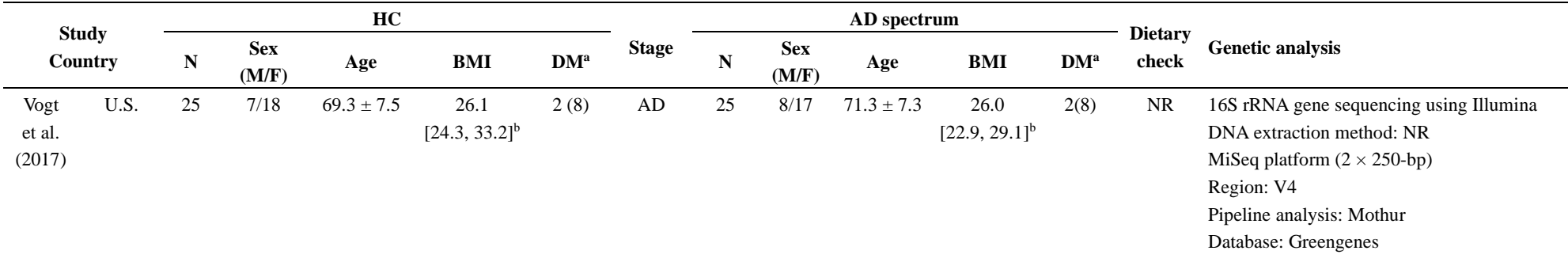

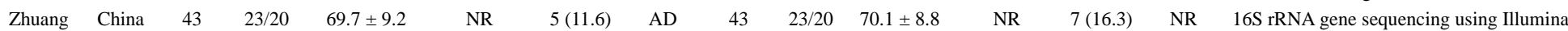

et al.

(2018)

Haran

et al.

(2019)

$\mathrm{Li}$

et al.

(2019)

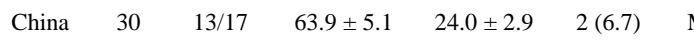

Liu

et al.

(2019)

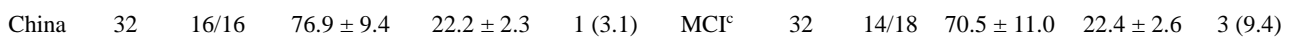

Nagpal

et al.

(2019)

Hou

et al.

(2021)

Liu

et al.

(2021)

Sheng

et al.

(2021)

Zhang

et al.

(2021)

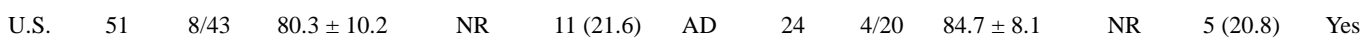

\begin{tabular}{|c|c|c|c|c|c|c|c|c|c|c|c|}
\hline & & & & & & $\mathrm{AD}$ & 30 & $15 / 15$ & $66.3 \pm 5.1$ & $23.0 \pm 3.5$ & $2(6.7)$ \\
\hline China & 32 & $16 / 16$ & $76.9 \pm 9.4$ & $22.2 \pm 2.3$ & $1(3.1)$ & $\mathrm{MCI}^{\mathrm{c}}$ & 32 & $14 / 18$ & $70.5 \pm 11.0$ & $22.4 \pm 2.6$ & $3(9.4)$ \\
\hline
\end{tabular}

(1)

$\begin{array}{lllllllllllll}\text { U.S. } & 6 & 2 / 4 & 65.2 \pm 3.7 & \text { NR } & \text { NR } & \text { MCI } & 11 & 3 / 8 & 64.3 \pm 7.7 & \text { NR } & \text { NR }\end{array}$

(

(n)

(n)

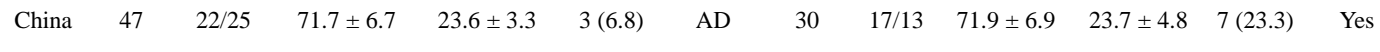

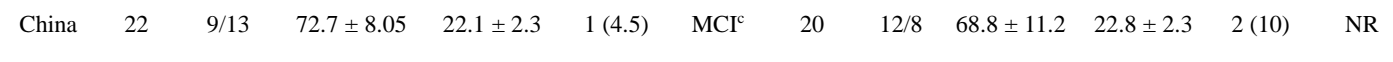

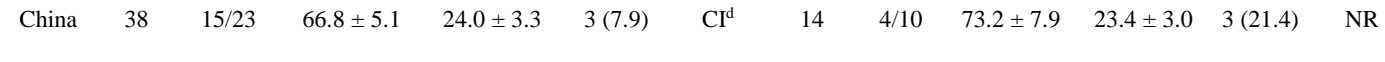

\begin{tabular}{|c|c|c|c|c|c|c|c|c|c|c|c|}
\hline China & 52 & $24 / 28$ & $62.5 \pm 4.0$ & $24.2 \pm 3.1$ & NR & MCI & 75 & $36 / 39$ & $62.0 \pm 4.1$ & $24.7 \pm 2.9$ & NR \\
\hline
\end{tabular}

\section{DNA extraction method: Power Soil Kit}

MiSeq platform ( 2 x 300-bp)

Region: V3-V4

Pipeline analysis: QIIME

Database: RDP

DNA extraction method: PowerMag soil DNA isolation kit

NextSeq 500 sequencing system ( 2 x 150-bp)

Region: NR

Pipeline analysis: KneadData

Database: NCBI bacterial genomes k-mer

16S rRNA gene sequencing using Illumina

DNA extraction method: QIAamp DNA Stool

Mini Kit

MiSeq platform ( 2 x 300-bp)

Region: V3-V4

Pipeline analysis: NR

Database: NR

16S rRNA gene sequencing using Illumina

DNA extraction method: DNA extraction kit

MiSeq platform

Region: V3-V4

Pipeline analysis: QIIME

Database: Greengenes

16S rRNA gene sequencing using Illumina

DNA extraction method: QiaAmp PowerFecal

DNA kit

MiSeq platform ( 2 x 300-bp)

Region: V4

Pipeline analysis: QIIME

Database: Greengenes

16S rRNA gene sequencing using Illumina

DNA extraction method: E.Z.N.A Stool

Extraction Kit

MiSeq platform ( 2 x 300-bp)

Region: V3-V4

Pipeline analysis: UPARSE

Database: Greengenes

16S rRNA gene sequencing using Illumina

DNA extraction method: DNA extraction kit

MiSeq platform

Region: V3-V4

Pipeline analysis: QIIME

Database: Greengenes

16S rRNA gene sequencing using Illumina

DNA extraction method: QIAamp DNA Stool

Mini Kit

MiSeq platform ( 2 x 300-bp)

Region: V3-V4

Pipeline analysis: NR

Database: RDP

16S rRNA gene sequencing using Illumina

DNA extraction method: Power Fecal DNA

Isolation Kit

HiSeq platform

Region: V4 
Abbreviations: HC: healthy control; $\mathrm{MCl}$ : mild cognitive impairment; AD: Alzheimer's disease; BMI: Body Mass Index; DM: diabetes mellitus; M: male; F: female; NR: not reported; QIIME: Quantitative Insights Into Microbial Ecology; RDP: Ribosomal Database Project. aDM was presented as $\mathrm{n}$ (\%); ${ }^{\mathrm{b}} \mathrm{BMI}$ was presented as median [interquartile range]; 解nestic

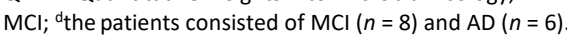

$p=0.030 ; n=5)$ and Simpson index (Hedges' $\mathrm{g}=$ $0.395 ; 95 \% \mathrm{CI}=0.116$ to $0.674 ; p=0.005 ; n=3)$.

Among all the included articles except for three studies [27, 35, 47], seven indicators of $\beta$ diversity were assessed (Table 2). The principal coordinate analyses based on both Weighted UniFrac distance and Unweighted UniFrac distances were most frequently measured. In terms of Weighted UniFrac distance, three studies revealed significant differences [24, 29, 46], while four studies revealed no significant differences between $\mathrm{HC}$ and $\mathrm{AD}$ spectrum [23, 25, 28, 45]. In terms of Unweighted UniFrac distances, two studies revealed significances [24, 29] while four studies revealed no significant differences between $\mathrm{HC}$ and $\mathrm{AD}$ spectrum $[23,25,28,45]$. In brief, the findings were inconsistent in our included studies.

\section{Primary outcome: overall effect sizes by disease}

In terms of the phylum level (Figure 3), the results showed more abundance of Proteobacteria (Hedges' g $=-0.349 ; 95 \% \mathrm{CI}=-0.604$ to $-0.095 ; p=0.007 ; n=6$ ) in AD spectrum versus HC. No significant difference was observed for Firmicutes between AD spectrum and HC $(p=0.833 ; n=8)$. After the exclusion of two outliers [24], a significantly less abundance of Firmicutes (Hedges' g $=0.538 ; 95 \% \mathrm{CI}=0.224$ to

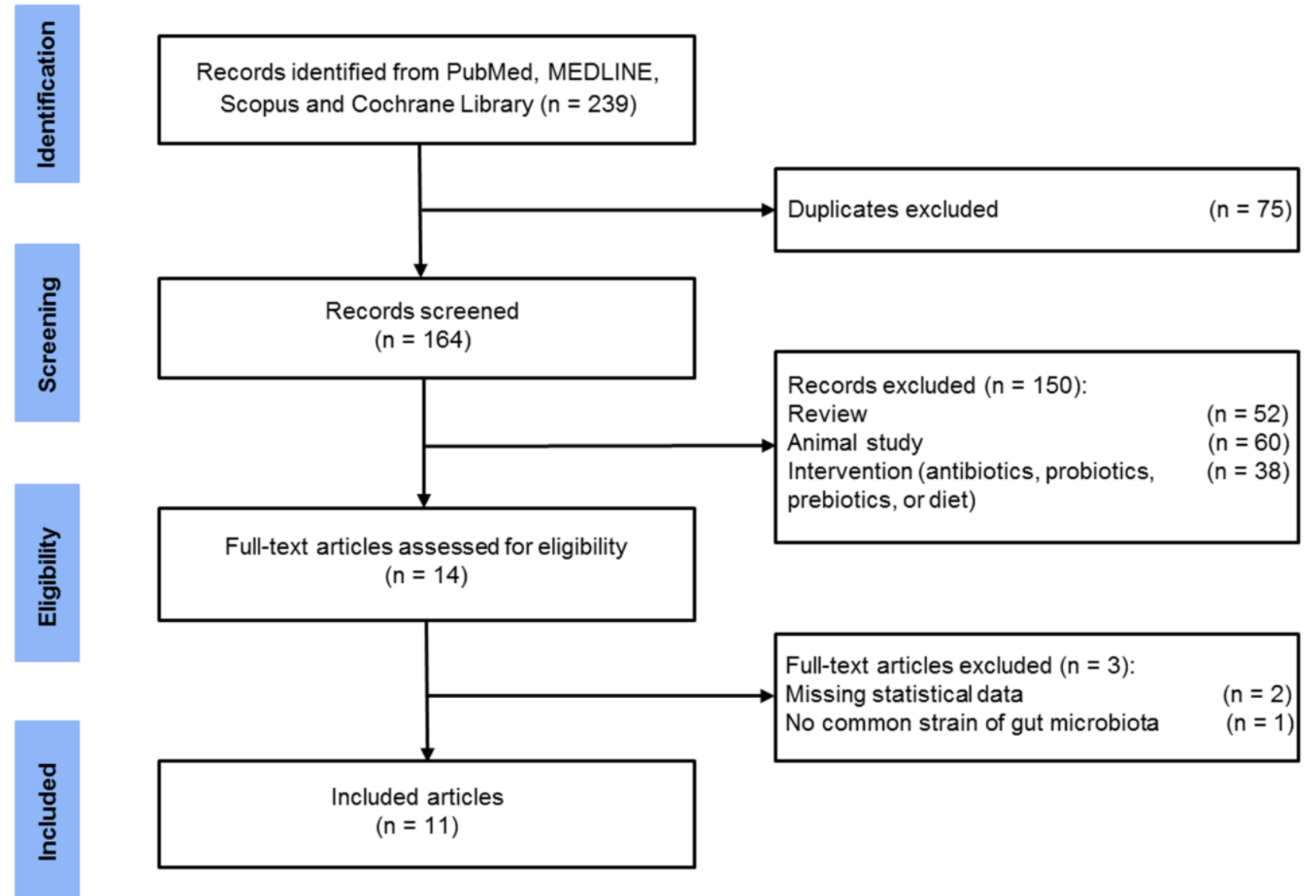

Figure 1. Flow diagram of selected studies. 
Table 2. Summary of beta diversity assessments in the included studies.

\begin{tabular}{|c|c|c|c|}
\hline Study & $\beta$ diversity & Findings & Statistic value \\
\hline $\begin{array}{l}\text { Vogt et al. } \\
(2017)\end{array}$ & $\begin{array}{l}\text { NMDS of Weighted UniFrac distances } \\
\text { NMDS of Unweighted UniFrac distances } \\
\text { NMDS based on Bray-Curtis dissimilarity }\end{array}$ & $\begin{array}{l}\text { A significant difference in gut microbial composition between } \mathrm{AD} \text { and } \mathrm{HC} \\
\text { A significant difference in gut microbial composition between } \mathrm{AD} \text { and } \mathrm{HC} \\
\text { A significant difference in gut microbial composition between } \mathrm{AD} \text { and } \mathrm{HC}\end{array}$ & $\begin{array}{l}p<0.001 \\
p<0.005 \\
p<0.001\end{array}$ \\
\hline $\begin{array}{l}\text { Li et al. } \\
(2019)\end{array}$ & PCoA of Weighted UniFrac distances & $\begin{array}{l}\text { A significant difference in gut microbial composition among } \mathrm{AD}, \mathrm{MCI} \text { and } \mathrm{HC} \\
\text { No significant difference in gut microbial composition between } \mathrm{AD} \text { and } \mathrm{MCI} \\
\text { A significant difference in gut microbial composition among } \mathrm{AD}, \mathrm{MCI} \text { and } \mathrm{HC} \\
\text { No significant difference in gut microbial composition between } \mathrm{AD} \text { and MCI }\end{array}$ & $\begin{array}{l}p=0.001 \\
\mathrm{NR} \\
p=0.001 \\
\mathrm{NR}\end{array}$ \\
\hline $\begin{array}{l}\text { Liu et al. } \\
\text { (2019) }\end{array}$ & $\begin{array}{l}\text { PCoA of Weighted UniFrac distances } \\
\text { PCoA of Unweighted UniFrac distances } \\
\text { PCoA based on Bray-Curtis dissimilarity }\end{array}$ & $\begin{array}{l}\text { No significant difference in gut microbial composition among } \mathrm{AD}, \mathrm{MCI}^{\mathrm{a}} \text { and } \mathrm{HC} \\
\text { No significant difference in gut microbial composition among } \mathrm{AD}, \mathrm{MCI}^{\mathrm{a}} \text { and } \mathrm{HC} \\
\text { A significant difference in gut microbial composition between } \mathrm{AD} \text { and } \mathrm{HC} \\
\text { A significant difference in gut microbial composition between } \mathrm{AD} \text { and } \mathrm{MCI}^{\mathrm{a}} \\
\text { A significant difference in gut microbial composition between } \mathrm{MCI}^{\mathrm{a}} \text { and } \mathrm{HC}\end{array}$ & $\begin{array}{l}\text { NR } \\
\text { NR } \\
p=0.017 \\
p=0.005 \\
p=0.012\end{array}$ \\
\hline $\begin{array}{l}\text { Nagpal et al. } \\
(2019)\end{array}$ & $\begin{array}{l}\text { PCoA of Weighted UniFrac distances } \\
\text { PCoA of Unweighted UniFrac distances }\end{array}$ & $\begin{array}{l}\text { No significant difference between MCI and } \mathrm{HC} \\
\text { No significant difference between MCI and } \mathrm{HC} \\
\end{array}$ & $\begin{array}{l}\mathrm{NR} \\
\mathrm{NR}\end{array}$ \\
\hline $\begin{array}{l}\text { Hou et al. } \\
(2021)\end{array}$ & $\begin{array}{l}\text { PCoA of Weighted UniFrac distances } \\
\text { PCoA of Unweighted UniFrac distances } \\
\text { PCoA based on Bray-Curtis dissimilarity }\end{array}$ & $\begin{array}{l}\text { No significant difference in gut microbial composition between } \mathrm{AD} \text { and } \mathrm{HC} \\
\text { No significant difference in gut microbial composition between } \mathrm{AD} \text { and } \mathrm{HC} \\
\text { A slight difference in gut microbial composition between } \mathrm{AD} \text { and } \mathrm{HC}\end{array}$ & $\begin{array}{l}p=0.233 \\
p=0.065 \\
p=0.039\end{array}$ \\
\hline $\begin{array}{l}\text { Sheng et al. } \\
(2021)\end{array}$ & $\begin{array}{l}\text { PCoA of Weighted UniFrac distances } \\
\text { PCoA of Unweighted UniFrac distances } \\
\text { PCoA based on Bray-Curtis dissimilarity }\end{array}$ & $\begin{array}{l}\text { A marginal difference in gut microbial composition between } \mathrm{CI}^{\mathrm{b}} \text { and } \mathrm{HC} \\
\text { No significant difference in gut microbial composition among } \mathrm{CI}^{\mathrm{b}}, \mathrm{SCD} \text { and } \mathrm{HC} \\
\text { A significant difference in gut microbial composition between } \mathrm{CI}^{\mathrm{b}} \text { and } \mathrm{HC}\end{array}$ & $\begin{array}{l}p=0.053 \\
\mathrm{NR} \\
p=0.047\end{array}$ \\
\hline $\begin{array}{l}\text { Zhang et al. } \\
(2021)\end{array}$ & PCoA of Weighted UniFrac distances & A significant difference in gut microbial composition between $\mathrm{MCI}$ and $\mathrm{HC}$ & $p=0.008$ \\
\hline $\begin{array}{l}\text { Zhou et al. } \\
(2021)\end{array}$ & $\begin{array}{l}\text { PCoA of Weighted UniFrac distances } \\
\text { PCoA of Unweighted UniFrac distances } \\
\text { PLS-DA }\end{array}$ & $\begin{array}{l}\text { A significant difference in gut microbial composition between } \mathrm{AD} \text { and } \mathrm{HC} \\
\text { A significant difference in gut microbial composition between } \mathrm{AD} \text { and } \mathrm{HC} \\
\text { A clear difference in gut microbial composition between } \mathrm{AD} \text { and } \mathrm{HC}\end{array}$ & $\begin{array}{l}p=0.026 \\
p<0.001 \\
\text { NR }\end{array}$ \\
\hline
\end{tabular}

Abbreviations: $\mathrm{HC}$ : healthy control; $\mathrm{MCl}$ : mild cognitive impairment; $\mathrm{AD}$ : Alzheimer's disease; SCD: subjective cognitive decline; ACE: Abundance-based Coverage Estimator; NMDS: Non-metric multidimensional scaling; PCoA: Principal Coordinate Analysis; PLS-DA: Partial Least Squares Discriminant Analysis. amnestic $\mathrm{MCl}$; bthe patients consisted of $\mathrm{MCl}(n=8)$ and $\mathrm{AD}(n=6)$.

$0.853 ; p=0.001 ; n=6)$ was observed in $\mathrm{AD}$ spectrum versus HC. The abundance of Bacteroidetes and Actinobacteria did not show obvious difference between $\mathrm{AD}$ spectrum and $\mathrm{HC}$.

In terms of the class level (Figure 4), the abundance of Bacteroidia, Clostridia, and Gammaproteobacteria did not show significant differences between AD spectrum and $\mathrm{HC}$.

In terms of the order level (Figure 5), the differences of abundance in Bacteroidales, Clostridiales, and Enterobacteriale were not significant in patients with $\mathrm{AD}$ spectrum as compared with $\mathrm{HC}$.

In terms of the family level (Figure 6), the Hedges' $\mathrm{g}$ effect size was 1.061 with $95 \% \mathrm{CI}=0.555$ to 1.568 ( $p<$ $0.001, n=4)$ for the Clostridiaceae, suggesting a less abundant level of this GM strain in AD spectrum versus HC. The difference of the abundance in Lachnospiraceae was not significant between $\mathrm{AD}$ spectrum and $\mathrm{HC}(p=0.763, n=7)$. After the exclusion of two outliers [24], we discovered a less abundant level of Lachnospiraceae (Hedges' $\mathrm{g}=0.632 ; 95 \% \mathrm{CI}=$ 0.402 to $0.862 ; p<0.001 ; n=5$ ) in $\mathrm{AD}$ spectrum versus HC. The abundance of Rikenellaceae did not show obvious differences between these two groups ( $p=$ $0.459 ; n=4)$. After the exclusion of one outlier [26], the pooled effect size was $0.797(95 \% \mathrm{CI}=0.305$ to 1.289 ; $p=0.002 ; n=3$ ), suggesting less abundant of this GM strain in $\mathrm{AD}$ spectrum versus $\mathrm{HC}$. No obvious differences were found for Bacteroidaceae, Enterobacteriaceae, and Ruminococcaceae between these two groups.

In terms of the genus level (Figure 7), a more abundant level of Phascolarctobacterium (Hedges' $\mathrm{g}=-0.852$; $95 \% \mathrm{CI}=-1.348$ to $-0.357 ; p=0.001 ; n=5$ ) was found in $\mathrm{AD}$ spectrum versus HC. The abundance of Bifidobacterium did not show obvious differences between $\mathrm{AD}$ spectrum and $\mathrm{HC}(p=0.728 ; n=4)$. After the exclusion of one outlier [26], a significantly more abundant level of Bifidobacterium (Hedges' $\mathrm{g}=-0.608$; $95 \% \mathrm{CI}=-0.886$ to $-0.330 ; p<0.001 ; n=3$ ) was detected in AD spectrum versus HC. The abundance of Alistipes, Bacteroides, and Blautia did not show significant differences between these two groups.

\section{Secondary outcome: effect sizes by country}

The pooled effect size for Bacteroides was not significant in the comparison between $\mathrm{HC}$ and $\mathrm{AD}$ spectrum (Figure 7). However, when country was considered as a moderator, the pooled effect sizes for U.S. $(n=2)$ and for China $(n=6)$ were -0.781 (with $95 \%$ CI from -1.301 to $-0.26, p=0.003$ ) and 0.027 (with $95 \%$ CI from -1.194 to 
$1.249, p=0.965)$, respectively. In brief, compared with $\mathrm{HC}$, the American patients with AD spectrum showed more abundance of Bacteroides, but such as pattern was not found for the Chinese patients (Table 3 ).

It was also interesting to note that in terms of Alistipes, the effect size for U.S. was -1.035 (with $95 \%$ CI from
-1.461 to $-0.609, p<0.001 ; n=2$ ), suggesting more abundant of this GM strain for American patients with $\mathrm{AD}$ spectrum. However, the overall effect size for China was 0.792 (with $95 \%$ CI from 0.287 to $1.296, p$ $=0.002 ; n=3$ ), suggesting less abundant of this GM strain for Chinese patients with $\mathrm{AD}$ spectrum (Table 3).

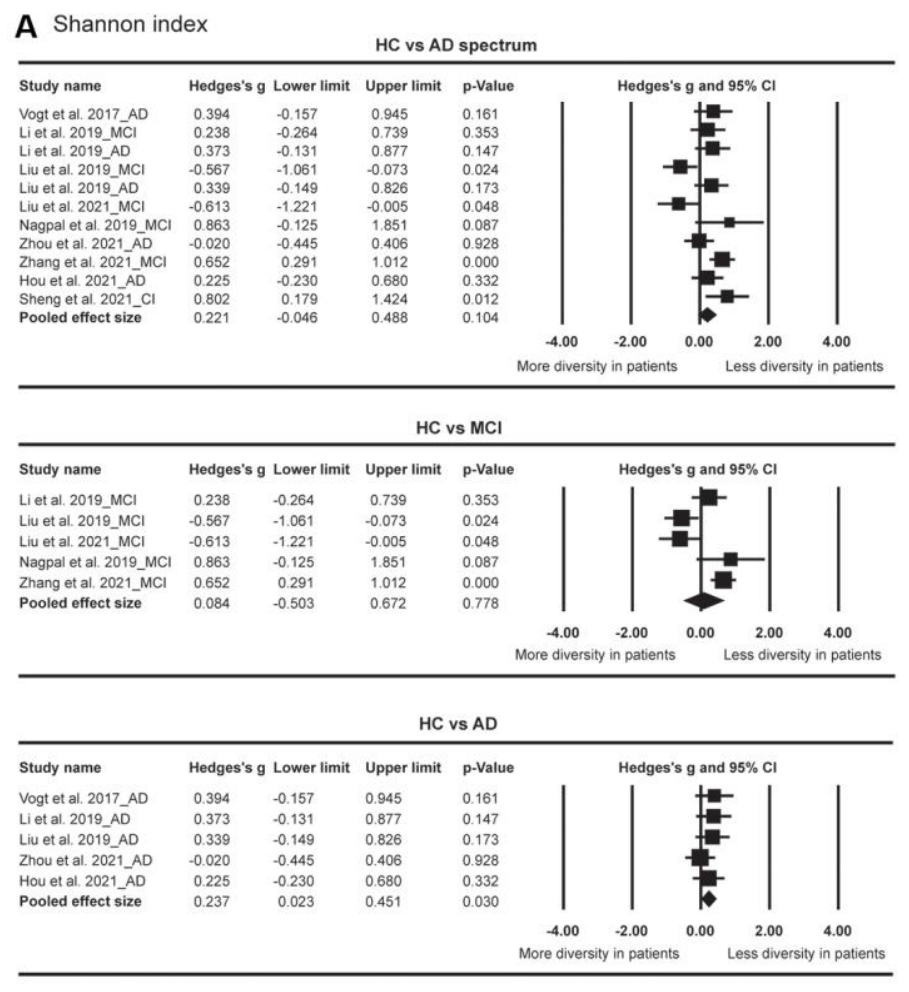

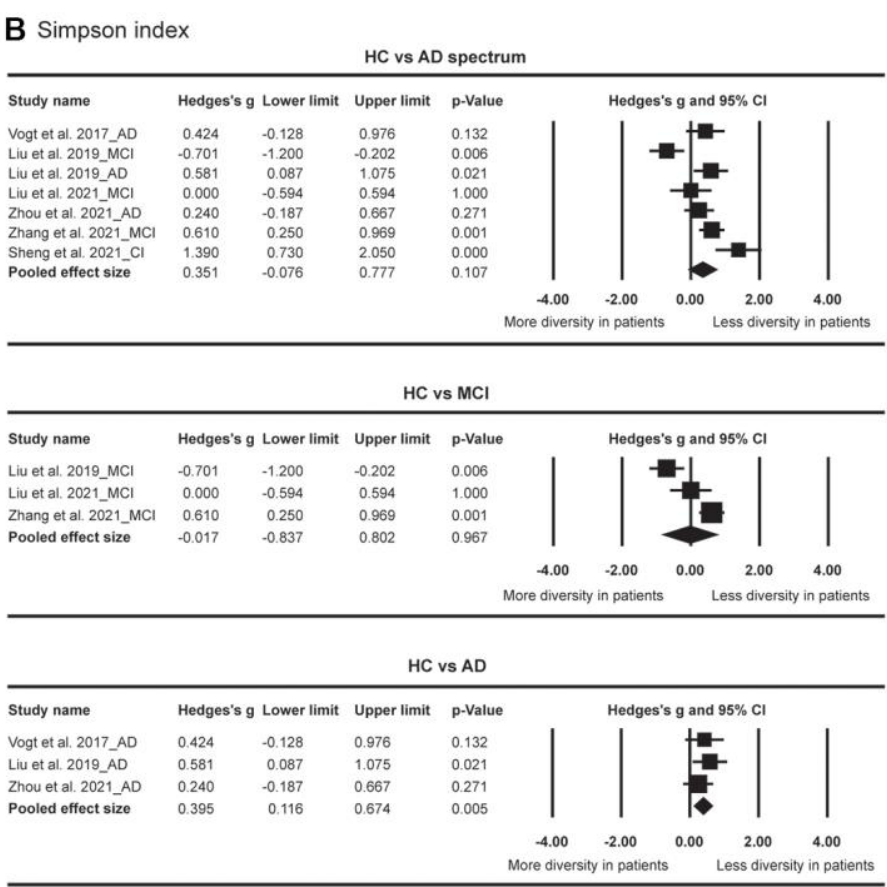

Figure 2. Forest plots of Shannon index (A) and Simpson index (B) in the comparisons between healthy controls (HC) and Alzheimer's disease $(A D)$ spectrum. Patients with $A D$ spectrum consisted of mild cognitive impairments (MCI) and AD. 
Table 3. Summary of effect sizes with $95 \% \mathrm{Cl}$ when country is considered as a moderator.

\begin{tabular}{|c|c|c|c|c|c|c|}
\hline & \multicolumn{3}{|c|}{ U.S. } & \multicolumn{3}{|c|}{ China } \\
\hline & Hedges' g & $95 \% \mathrm{CI}$ & $p$ & Hedges' $\mathrm{g}$ & $95 \% \mathrm{CI}$ & $p$ \\
\hline P_Bacteroidetes & -0.257 & {$[-2.086,1.572]$} & 0.783 & 0.983 & {$[-0.108,2.075]$} & 0.077 \\
\hline G_Alistipes & -1.035 & {$[-1.461,-0.609]$} & $<0.001$ & 0.792 & {$[0.287,1.296]$} & 0.002 \\
\hline G_Bacteroides & -0.781 & {$[-1.301,-0.260]$} & 0.003 & 0.027 & {$[-1.194,1.249]$} & 0.965 \\
\hline
\end{tabular}

Abbreviations: $\mathrm{Cl}$ : confidence interval; P: phylum; G: Genus. The effect sizes were reported only when the number of investigations $\geqq 2$ in both countries.

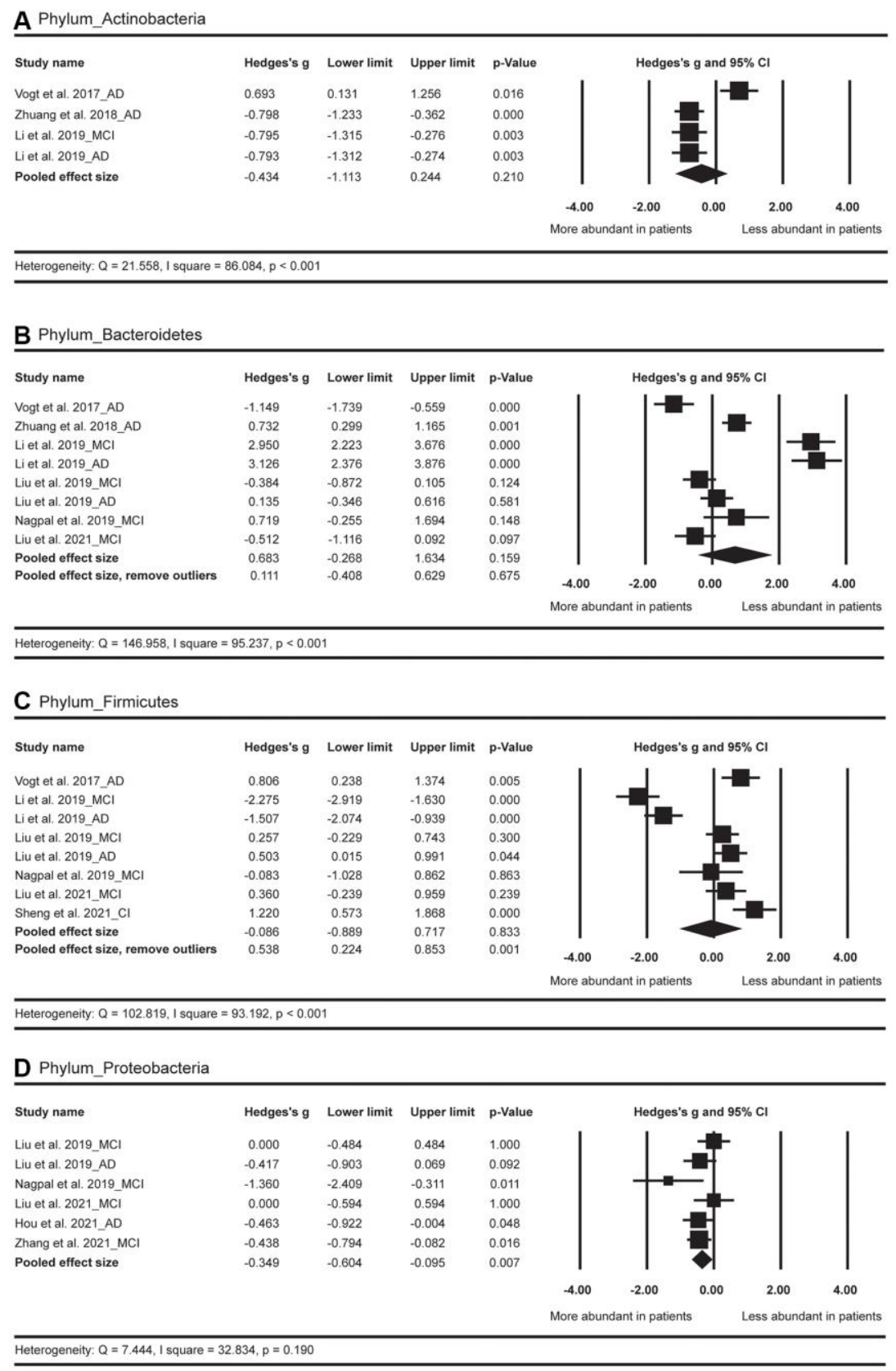

Figure 3. Forest plots of alterations of gut microbiota in the phylum level, including Actinobacteria (A), Bacteroidetes (B), Firmicutes (C), and Proteobacteria (D). Abbreviations: AD: Alzheimer's disease; $\mathrm{MCl}$ : mild cognitive impairments; $\mathrm{Cl}$ : cognitive impairments. 
Different countries did not significantly modulate the abundance of Bacteroidetes, Firmicutes, and Phascolarctobacterium in the comparisons between HC and AD spectrum.

\section{Secondary outcome: Effect sizes by clinical stage}

The abundance of Proteobacteria was increased in the patients with AD spectrum. However, the significance was only found in the comparison between $\mathrm{HC}$ and AD (Hedges' $\mathrm{g}=-0.441,95 \% \mathrm{CI}$ $=-0.775$ to $-0.108, p=0.01 ; n=2$ ), but not in the comparison between $\mathrm{HC}$ and $\mathrm{MCI}$ (Hedges' $\mathrm{g}=$ $-0.317,95 \% \mathrm{CI}=-0.739$ to $0.106, p=0.142 ; n=$ 4). Similar trend of abundance was found in the Phascolarctobacterium, revealing that the abundance of this GM was significantly increased in patients with MCI versus HC (Hedges' $\mathrm{g}=-0.763$, $95 \% \mathrm{CI}=-1.277$ to $-0.248, p=0.004 ; n=3$ ) (Table 4).

A Class_Bacteroidia

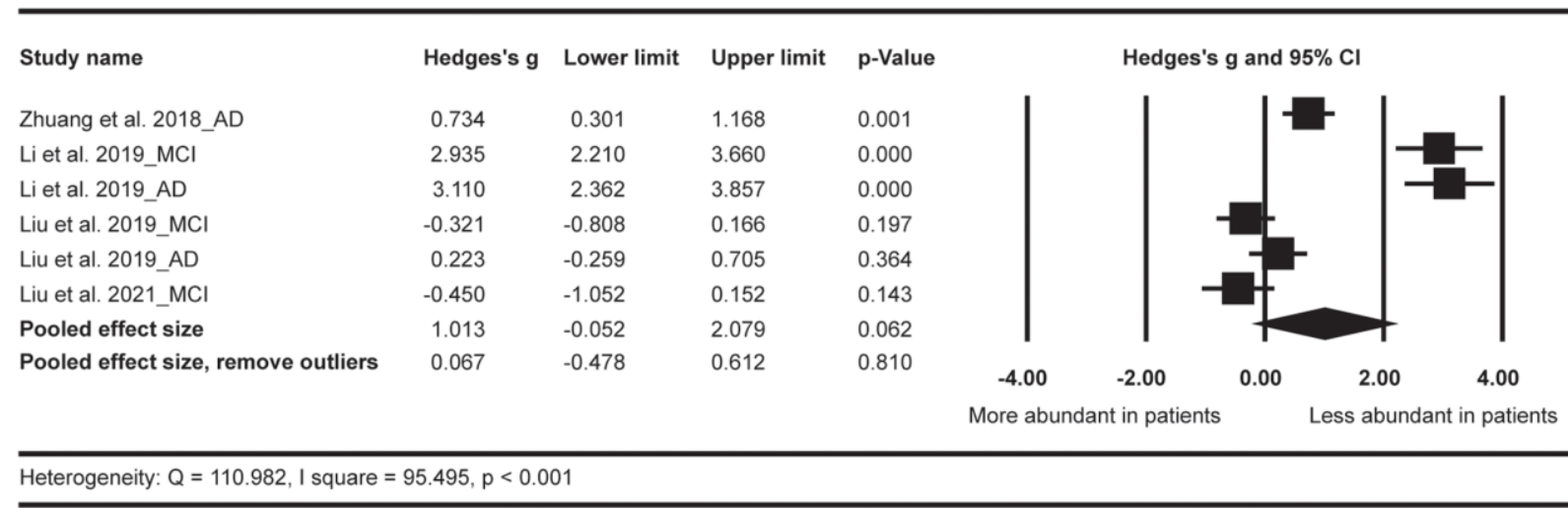

B Class_Clostridia

$\begin{array}{lcccc}\text { Study name } & \text { Hedges's g } & \text { Lower limit } & \text { Upper limit } & \text { p-Value } \\ \text { Li et al. 2019_MCl } & -1.717 & -2.303 & -1.130 & 0.000 \\ \text { Li et al. 2019_AD } & -1.168 & -1.709 & -0.627 & 0.000 \\ \text { Liu et al. 2019_MCI } & 0.214 & -0.271 & 0.700 & 0.387 \\ \text { Liu et al. 2019_AD } & 0.675 & 0.180 & 1.169 & 0.007 \\ \text { Liu et al. 2021_MCl } & 0.321 & -0.277 & 0.919 & 0.293 \\ \text { Sheng et al. 2021_Cl } & 1.072 & 0.434 & 1.710 & 0.001 \\ \text { Pooled effect size } & -0.101 & -0.944 & 0.742 & 0.814 \\ \text { Pooled effect size, remove outliers } & 0.217 & -0.510 & 0.943 & 0.559\end{array}$

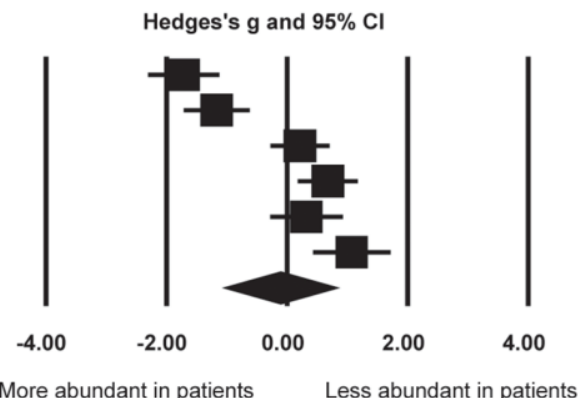

More abundant in patients Less abundant in patients

Heterogeneity: $Q=70.062$, I square $=92.863, p<0.001$

C Class_Gammaproteobacteria

\begin{tabular}{llllll}
\hline Study name & Hedges's g & Lower limit & Upper limit & $\mathbf{p}$-Value \\
Liu et al. 2019_MCl & 0.090 & -0.394 & 0.574 & 0.716 \\
Liu et al. 2019_AD & -0.361 & -0.846 & 0.123 & 0.144 \\
Liu et al. 2021_MCl & 0.038 & -0.556 & 0.632 & 0.900 \\
Zhang et al. 2021_MCl & -0.404 & -0.759 & -0.049 & 0.026 \\
Pooled effect size & -0.208 & -0.464 & 0.047 & 0.110 & \\
\hline
\end{tabular}

Figure 4. Forest plots of alterations of gut microbiota in the class level, including Bacteroidia (A), Clostridia (B), and Gammaproteobacteria (C). Abbreviations: AD: Alzheimer's disease; $\mathrm{MCl}$ : mild cognitive impairments; $\mathrm{Cl}$ : cognitive impairments. 
In contrast, we found a trend toward decreased abundance of Clostridiaceae in the patients with MCI (Hedges' $\mathrm{g}=0.700,95 \% \mathrm{CI}=-0.013$ to $1.413, p=$ $0.054 ; n=2$ ), which was more pronounced in the patients with $\mathrm{AD}$ (Hedges' $\mathrm{g}=1.406,95 \% \mathrm{CI}=1.001$ to $1.810, p<0.001 ; n=2$ ) (Table 4).

\section{Risk of bias}

The quality of the included studies is summarized in Supplementary Table 1. Each study was classified as low risk in five criteria. In the criteria of confounding variables, all studies, except for one [23], suffered from a high-risk bias due to the potential confounding factors (e.g., body mass index, diabetes and diet) on GM structure.

\section{Publication bias}

The Begg and Mazumdar rank correlations as well as Egger's regression intercept tests confirmed that most of these meta-analysis results were not significantly

A Order_Bacteroidales

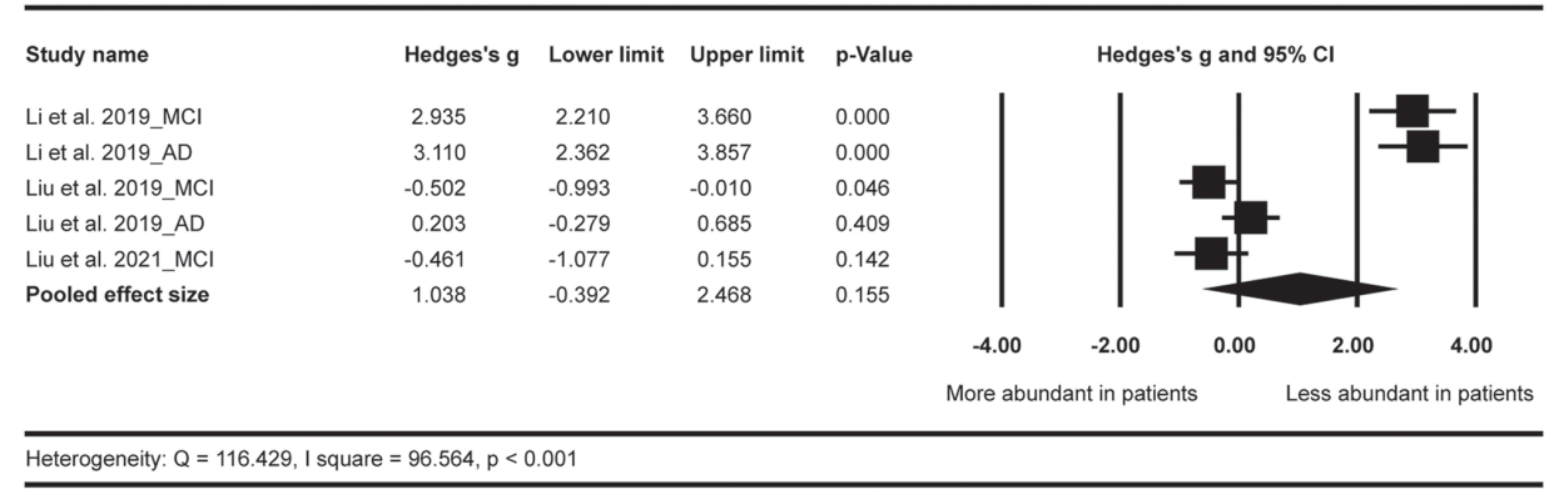

B Order_Clostridiales

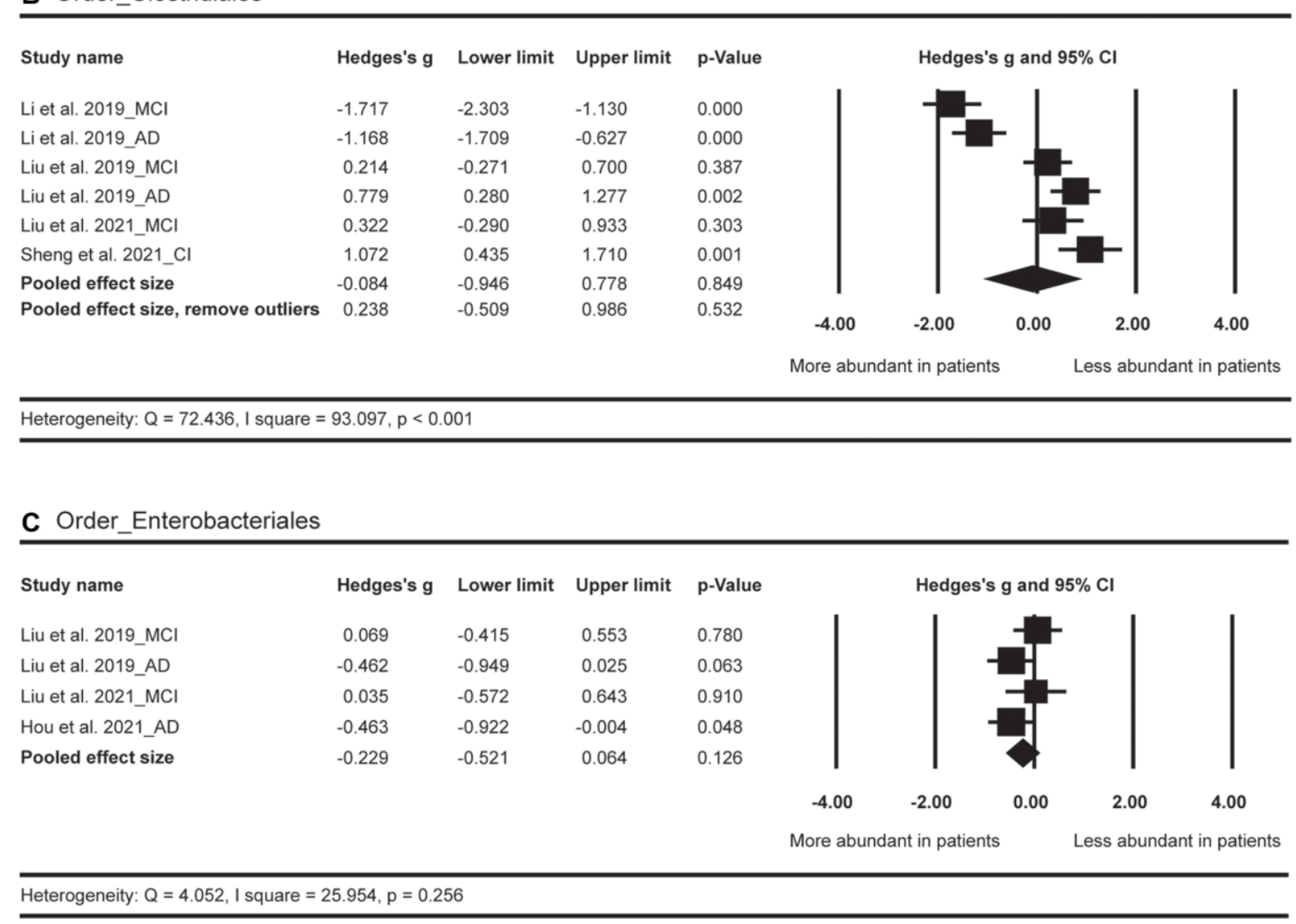

Figure 5. Forest plots of alterations of gut microbiota in the order level, including Bacteroidales (A), Clostridiales (B), and Enterobacteriale (C). Abbreviations: AD: Alzheimer's disease; $\mathrm{MCl}$ : mild cognitive impairments; $\mathrm{Cl}$ : cognitive impairments. 
Table 4. Summary of effect sizes with $95 \% \mathrm{Cl}$ when clinical stage is considered as a moderator.

\begin{tabular}{|c|c|c|c|c|c|c|}
\hline & \multicolumn{3}{|c|}{ HC vs. MCI } & \multicolumn{3}{|c|}{ HC vs. AD } \\
\hline & Hedges' $\mathrm{g}$ & $95 \% \mathrm{CI}$ & $p$ & Hedges' $\mathrm{g}$ & $95 \% \mathrm{CI}$ & $p$ \\
\hline P_Bacteroidetes & 0.680 & {$[-0.879,2.239]$} & 0.393 & 0.693 & {$[-0.712,2.099]$} & 0.334 \\
\hline P_Firmicutes & -0.434 & {$[-1.683,0.814]$} & 0.495 & -0.063 & {$[-1.438,1.312]$} & 0.928 \\
\hline P_Proteobacteria & -0.317 & {$[-0.739,0.106]$} & 0.142 & -0.441 & {$[-0.775,-0.108]$} & 0.010 \\
\hline C_Bacteroidia & 0.707 & {$[-1.228,2.642]$} & 0.474 & 1.323 & {$[-0.087,2.733]$} & 0.066 \\
\hline C_Clostridia & -0.390 & {$[-1.648,0.868]$} & 0.544 & -0.243 & {$[-2.049,1.562]$} & 0.792 \\
\hline O_Bacteroidales & 0.644 & {$[-1.372,2.660]$} & 0.531 & 1.642 & {$[-1.207,4.490]$} & 0.259 \\
\hline O_Clostridiales & -0.391 & {$[-1.655,0.874]$} & 0.545 & -0.192 & {$[-2.099,1.716]$} & 0.844 \\
\hline O_Enterobacteriales & 0.056 & {$[-0.323,0.434]$} & 0.773 & -0.462 & {$[-0.796,-0.128]$} & 0.007 \\
\hline F_Bacteroidaceae & -0.082 & {$[-1.727,1.564]$} & 0.922 & 0.500 & {$[-0.622,1.621]$} & 0.383 \\
\hline F_Clostridiaceae & 0.700 & {$[-0.013,1.413]$} & 0.054 & 1.406 & {$[1.001,1.810]$} & $<0.001$ \\
\hline F_Enterobacteriaceae & 0.278 & {$[-0.951,0.394]$} & 0.417 & -0.460 & {$[-0.794,-0.126]$} & 0.007 \\
\hline F_Lachnospiraceae & -0.016 & {$[-1.300,1.268]$} & 0.980 & -0.058 & {$[-1.156,1.040]$} & 0.917 \\
\hline F_Rikenellaceae & 0.716 & {$[0.007,1.426]$} & 0.048 & -0.086 & {$[-2.231,2.060]$} & 0.937 \\
\hline F_Ruminococcaceae & -0.296 & {$[-0.673,0.082]$} & 0.125 & 0.300 & {$[-0.856,1.456]$} & 0.611 \\
\hline G_Alistipes & 0.708 & {$[-0.018,1.435]$} & 0.056 & -0.374 & {$[-1.741,0.993]$} & 0.592 \\
\hline G_Bacteroides & -0.961 & {$[-3.516,1.594]$} & 0.461 & 0.262 & {$[-0.673,1.197]$} & 0.583 \\
\hline G_Blautia & 0.265 & {$[-0.633,1.162]$} & 0.563 & -0.370 & {$[-0.952,0.212]$} & 0.213 \\
\hline G_Phascolarctobacterium & -0.763 & {$[-1.277,-0.248]$} & 0.004 & -0.953 & {$[-2.166,0.260]$} & 0.124 \\
\hline
\end{tabular}

Abbreviations: Cl: confidence interval; P: Phylum; C: Class; O: Order; F: Family; G: Genus. The effect sizes were reported only when the number of investigations $\geqq 2$ in both diagnoses.

biased by publication errors. The adjusted Hedges' g was operated in $4 \mathrm{GM}$ strains, including Firmicutes, Gammaproteobacteria, Bacteroidales, and Enterobacteriale (Supplementary Table 2).

\section{DISCUSSION}

This study conducted meta-analysis to compare GM abundance between the patients with AD spectrum and $\mathrm{HC}$, and yielded four major insights into the nature of $\mathrm{GM}$ alterations in $\mathrm{AD}$ spectrum. First, patients with $\mathrm{AD}$, but not MCI, exhibited decreased GM diversity as compared to HC. Second, Proteobacteria, Bifidobacterium and Phascolarctobacterium were more abundant in $\mathrm{AD}$ spectrum, whereas Firmicutes, Clostridiaceae, Lachnospiraceae and Rikenellaceae were less abundant in AD spectrum compared to HC. Third, the abundance of Alistipes was significantly increased in American patients but significantly decreased in Chinese patients as compared to HC. Altered abundance of Bacteroides was only found in the American patients but not in the Chinese patients. Finally, the abundance of Proteobacteria and Phascolarctobacterium was progressively increased from $\mathrm{HC}$ to $\mathrm{AD}$ stage, while the abundance of Clostridiaceae was gradually reduced from $\mathrm{HC}$ to $\mathrm{AD}$ stage.

To our knowledge, the present meta-analysis is the first to assess $\alpha$ diversity and $\beta$ diversity in patients with $\mathrm{AD}$ spectrum. Generally, several studies have reported that alpha diversity is significantly decreased in patients with $\mathrm{AD}[25,26]$ but not in patients with MCI $[28,35]$. These findings were consistent with our results of metaanalysis, and there was also a trend toward a progressive decline from MCI to AD. Similarly, the decrease of $\alpha$ diversity was also found in other conditions, such as Parkinson's disease [48] and irritable bowel syndrome (IBS) [49]. In terms of $\beta$ diversity, further exploration is obviously needed to examine between $\mathrm{HC}$ and $\mathrm{AD}$ spectrum due to the extremely inconsistent findings.

The Proteobacteria is a major phylum of gram-negative bacteria [50]. Of note, the Proteobacteria member Escherichia coli-derived neurotoxins are correlated with $\mathrm{AD}$ neuropathology and increase the release of proinflammatory cytokines [44]. It has also been shown that an increased level of Proteobacteria was associated with pro-inflammatory dietary pattern (e.g., high-fat diet), and the abundance of Proteobacteria increased along with worse memory dysfunction [51, 52]. Taken together, our current finding that patients with $\mathrm{AD}$ spectrum showed abnormally more abundance of Proteobacteria was supported by previous literature.

The phylum Firmicutes serves a connection with inflammatory effects, the modulation of metabolic function and the production of SCFAs [53, 54]. Several lines of evidences have demonstrated that decreased Firmicutes was associated with the development of obesity and type 2 diabetes $[55,56]$. It was also important to note that insulin resistance might lead to cerebral glucose hypometabolism and enhanced $A \beta$ accumulation in asymptomatic middle-aged people with increased risk of $\mathrm{AD}[57,58]$. Furthermore, the abundance of 
Firmicutes was positively associated with the performance of executive function, suggesting that it is a kind of beneficial GM strain for the humans [45, 59].
The family Clostridiaceae performs a vital function on producing SCFAs, which can offer fuel sources for the host and protective effects on permeability of gut and

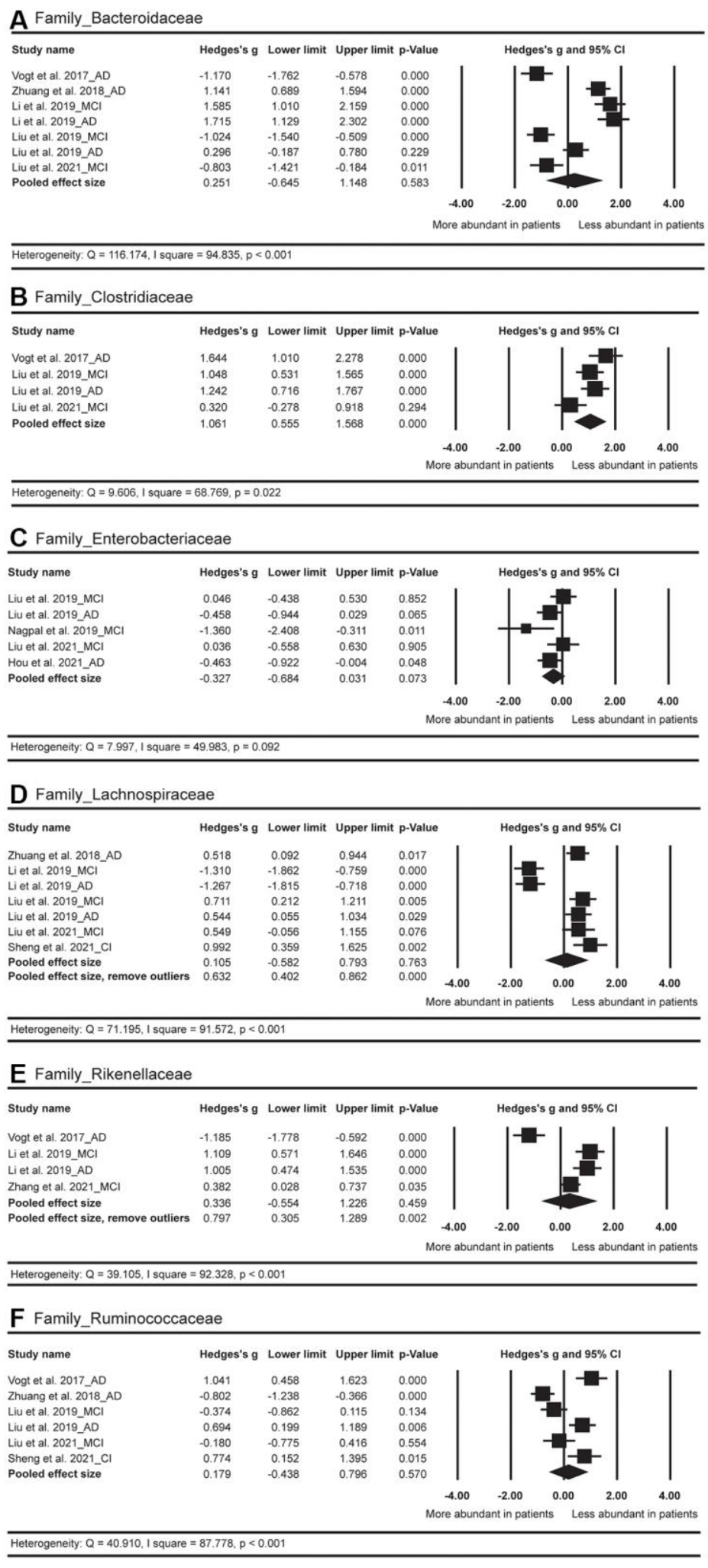

Figure 6. Forest plots of alterations of gut microbiota in the family level, including Bacteroidaceae (A), Clostridiaceae (B), Enterobacteriaceae (C), Lachnospiraceae (D), Rikenellaceae (E), and Ruminococcaceae (F). Abbreviations: AD: Alzheimer's disease; MCl: mild cognitive impairments; $\mathrm{Cl}$ : cognitive impairments. 
BBB [60]. Moreover, it has been shown that Clostridiaceae was the producers of indole-3-propionic acid, which could prevent oxidative injuries of primary neurons from $A \beta$ [61]. Decrease of Clostridiaceae may impair cognitive function and intrinsic brain activities as evident by the results of resting-state functional magnetic resonance imaging [35]. Correspondingly, the family Lachnospiraceae is the producer of butyrate, which participates in anti-inflammatory reactions, and in turn maintains the gut barrier $[62,63]$. A number of

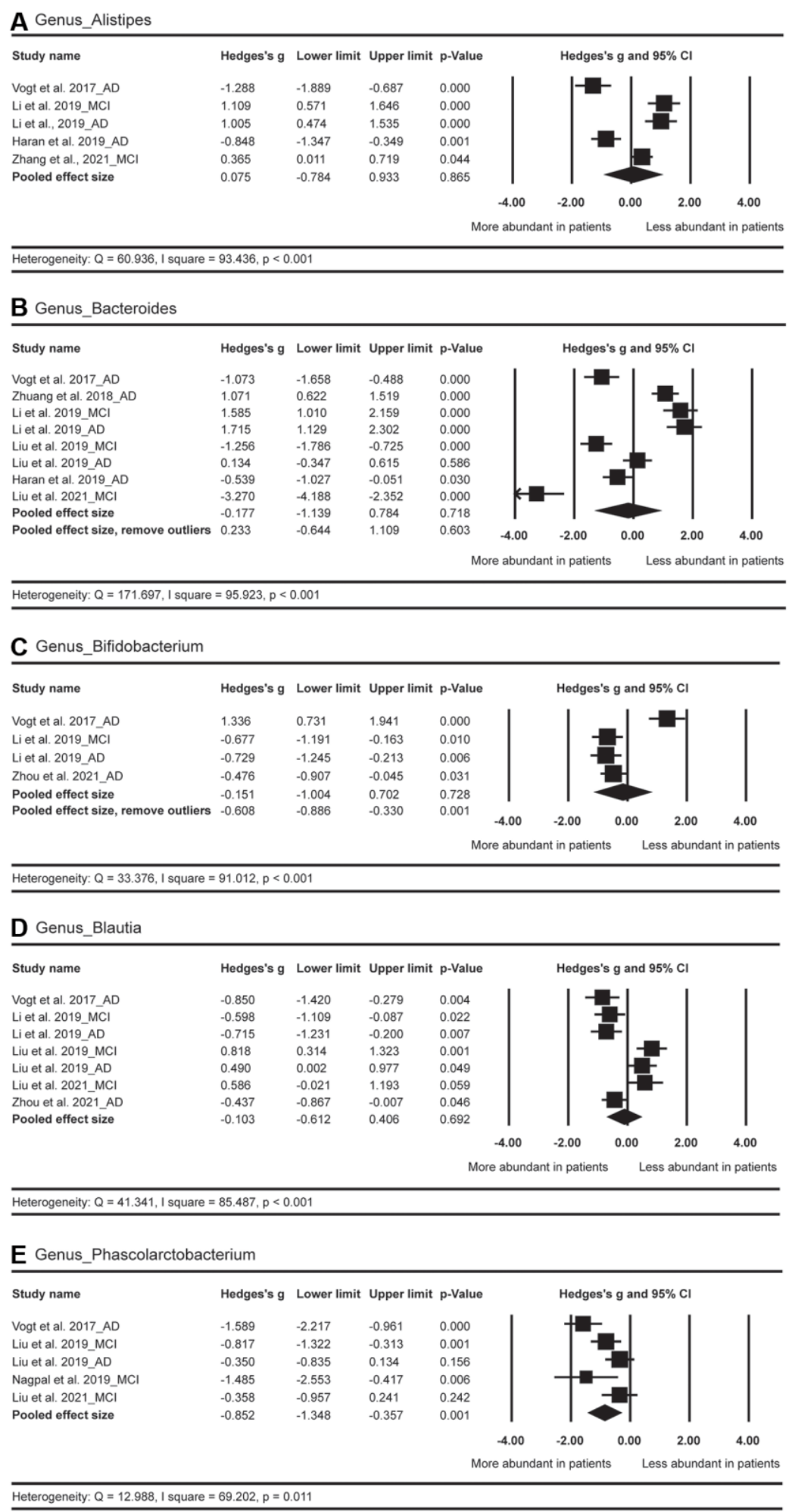

Figure 7. Forest plots of alterations of gut microbiota in the genus level, including Alistipes (A), Bacteroides (B), Bifidobacterium (C), Blautia (D), and Phascolarctobacterium (E). Abbreviations: AD: Alzheimer's disease; $\mathrm{MCl}$ : mild cognitive impairments. 
studies have discovered that less abundance of Lachnospiraceae would result in insulin resistance, disruptions of homeostasis within the CNS and exacerbation of AD neuropathology [55, 64]. Hence, the Lachnospiraceae was considered as an advantageous GM strain.

The genus Bifidobacterium is involved in the production of acetate and $\gamma$-aminobutyric acid, which has neuroprotective effects on the hosts $[65,66]$. It is worth mentioning that Bifidobacterium members have been associated with anti-inflammatory effects and reduced permeability of gut [67]. In addition, animal studies have shown that Bifidobacterium obviously alleviated the development of AD pathologies [3]. It has also been reported that probiotics with Bifidobacterium ameliorated cognitive impairments in patients with $\mathrm{AD}$ [68]. However, our meta-analysis exhibited an unexpected result that an increase of Bifidobacterium was found in subjects with AD spectrum. This finding might imply the potential gut-brain self-preventative mechanism to rebuild intestinal homeostasis [69]. Nevertheless, it merits future research with a larger sample size to have an in-depth investigation.

The composition and abundance of GM may be influenced by many factors such as age, geographical areas, dietary pattern, and chronic stress. In general, the random-effect sizes for Bacteroides and Alistipes in $\mathrm{AD}$ spectrum did not show obvious differences as compared with HC. These non-significant results were potentially owing to large heterogeneities among the included studies. When considering the country (i.e., China and U.S.) as a moderator, our meta-analysis demonstrated an overgrowth of Bacteroides and Alistipes in American patients; however, this pattern was not observed in Chinese patients. A previous meta-analysis study has found that Chinese patients with IBS did not show obvious changes of abundance in Bacteroides compared to $\mathrm{HC}$; inversely, enriched abundance of Bacteroides was observed in patients with IBS from other areas such as U.S. and Finland [49]. It has also been reported that enhanced Bacteroidetes (genus Bacteroides) members might be a possible signature for $\mathrm{AD}$ spectrum since certain members of this phylum are opportunistic pathogens, especially Bacteroides fragilis (B. fragilis) [70]. Interestingly, $B$. fragilis can be divided into two strains: non-toxigenic $B$. fragilis (NTBF) and enterotoxigenic $B$. fragilis (ETBF). NTBF participates in suppression of colitis and strengthening gut barrier; in contrast, ETBF secretes B. fragilis toxins and is highly associated with inflammatory bowel disease [71, 72]. Up to the present, there has been no reasonable interpretation to account for an increased level of Alistipes abundance in patients with $\mathrm{AD}$ spectrum. It will be a valuable issue for future studies to validate our meta-analysis finding.

We considered the clinical stage as another moderator in the present study. Compared to HC, Proteobacteria, and Phascolarctobacterium were gradually enhanced from $\mathrm{MCI}$ to $\mathrm{AD}$ stage. The pro-inflammatory Proteobacteria has been suggested as a predictor for $\mathrm{AD}$ pathogenesis $[23,35]$. In contrast, Clostridiaceae was found to be progressively reduced from MCI to AD patients. The abundance of beneficial Clostridiaceae has been reported to be significantly decreased in patients with $\mathrm{AD}$, suggesting that it is a distinctive biomarker in predicting the development of $\mathrm{AD}$. In addition, the results of some GM strains in the comparisons of $\mathrm{HC}$ versus $\mathrm{MCI}$ and $\mathrm{HC}$ versus $\mathrm{AD}$ did not show gradient changes. The abundance of Enterobacteriales was significantly increased in patients with $\mathrm{AD}$, but a little decreased in patients with MCI. This non-gradient pattern from $\mathrm{HC}$ to $\mathrm{AD}$ was in line with a previous study $[25,35]$. The abundance of Rikenellaceae was significantly reduced in patients with $\mathrm{MCI}$, but a little enhanced in AD patients, suggesting that the association between Rikenellaceae and $\mathrm{AD}$ pathogenesis needs further exploration.

In spite of these interesting findings, our study was not without limitations. First, the generalization of these results to other populations is questionable because the vast majority of included studies originated from just two countries. Second, many of the studies suffer from significant sources of bias. There were obvious statistical heterogeneities among the included studies, which could be attributed to differences in dietary pattern, geographical background, center settings, and inclusion criteria of AD spectrum including various regimens, medication doses, illness duration, etc. For example, only three studies [23, 46, 47] in our metaanalysis conducted the dietary assessments. Nevertheless, we applied the random-model to estimate the effect sizes to reduce the influences of the heterogeneities on our results. Third, we manually extracted the necessary data from the bar graphs in several studies, which might lead to another type of bias. However, this procedure was performed by two reviewers with sufficient discussion and consensus. Hence, we reasoned that the direction of the statistical significance in the between-group comparisons would not be substantially affected since we performed this method uniformly across the studies. Fourth, the effects in many occasions were assessed by very few studies and thus the current results should be interpreted with cautions. It merits future research to include more studies to provide stronger evidence on this issue. Fifth, different methods of nucleic acid extraction and gene sequencing (Table 1) are also the potential biases on the 
results. For example, the differences of GM diversity between $\mathrm{HC}$ and $\mathrm{AD}$ spectrum might be greater based on the V3-V4 region than those on the V4 region. However, the limited number of studies (three with V4 region and seven with $\mathrm{V} 3-\mathrm{V} 4$ region) impeded us to perform additional analysis.

In conclusion, we demonstrated that Proteobacteria, Bifidobacterium and Phascolarctobacterium were significantly higher abundant in patients with $\mathrm{AD}$ spectrum, whereas Firmicutes, Clostridiaceae, Lachnospiraceae and Rikenellaceae were significantly lower in patients with $\mathrm{AD}$ spectrum compared to HC. Moreover, the dysbiosis of these GM can be viewed as an environmental factor of the $\mathrm{AD}$ initiation and progression. In the future, a larger cohort study is needed to further examine the differences of GM in $\mathrm{AD}$ spectrum.

\section{AUTHOR CONTRIBUTIONS}

Conceived and designed the work: $\mathrm{CCH}, \mathrm{RN}, \mathrm{CHC}$; Acquired the data: $\mathrm{CCH}, \mathrm{CHC}$; Analyzed the data: $\mathrm{CCH}, \mathrm{RN}, \mathrm{CHC}$; Participated in the discussion and provided the comments: $\mathrm{CCH}, \mathrm{CCC}, \mathrm{CWH}, \mathrm{RN}, \mathrm{CHC}$; Wrote the paper: $\mathrm{CCH}, \mathrm{CHC}$; All of the authors have read and approved the manuscript.

\section{CONFLICTS OF INTEREST}

The authors declare no conflicts of interest related to this study.

\section{FUNDING}

This work was supported by Chang Gung Memorial Hospital (CMRPD1K0061, CMRPD1K0581), Chang Gung University (BMRPE25), Healthy Aging Research Center, Chang Gung University from the Featured Areas Research Center Program within the Framework of the Higher Education Sprout Project by the Ministry of Education (MOE) in Taiwan (EMRPD1K0431), Ministry of Science and Technology (MOST-105-2628B-182-004-MY3, MOST-108-2628-B-182-002, MOST109-2628-B-182-012, MOST-110-2628-B-182-010), Taiwan.

\section{REFERENCES}

1. Dubois B, Hampel H, Feldman HH, Scheltens $P$, Aisen $P$, Andrieu S, Bakardjian $H$, Benali $H$, Bertram L, Blennow K, Broich K, Cavedo E, Crutch S, et al, and Proceedings of the Meeting of the International Working Group (IWG) and the American Alzheimer's Association on "The Preclinical State of AD"; July 23, 2015; Washington DC, USA. Preclinical Alzheimer's disease: Definition, natural history, and diagnostic criteria. Alzheimers Dement. 2016; 12:292-323.

https://doi.org/10.1016/j.jalz.2016.02.002

PMID:27012484

2. Zhang ZH, Wu QY, Zheng R, Chen C, Chen Y, Liu Q, Hoffmann PR, Ni JZ, Song GL. Selenomethionine Mitigates Cognitive Decline by Targeting Both Tau Hyperphosphorylation and Autophagic Clearance in an Alzheimer's Disease Mouse Model. J Neurosci. 2017; 37:2449-62. https://doi.org/10.1523/JNEUROSCI.3229-16.2017 PMID:28137967

3. Bonfili L, Cecarini V, Cuccioloni $M$, Angeletti $M$, Berardi S, Scarpona S, Rossi G, Eleuteri AM. SLAB51 Probiotic Formulation Activates SIRT1 Pathway Promoting Antioxidant and Neuroprotective Effects in an AD Mouse Model. Mol Neurobiol. 2018; 55:79878000.

https://doi.org/10.1007/s12035-018-0973-4 PMID:29492848

4. Kim MS, Kim Y, Choi H, Kim W, Park S, Lee D, Kim DK, Kim HJ, Choi H, Hyun DW, Lee JY, Choi EY, Lee DS, et al. Transfer of a healthy microbiota reduces amyloid and tau pathology in an Alzheimer's disease animal model. Gut. 2020; 69:283-94.

https://doi.org/10.1136/gutinl-2018-317431 PMID:31471351

5. Zhang L, Wang $Y$, Xiayu $X$, Shi $C$, Chen $W$, Song $N$, Fu $X$, Zhou R, Xu YF, Huang L, Zhu H, Han Y, Qin C. Altered Gut Microbiota in a Mouse Model of Alzheimer's Disease. J Alzheimers Dis. 2017; 60:124157.

https://doi.org/10.3233/JAD-170020

PMID:29036812

6. Chow J, Lee SM, Shen Y, Khosravi A, Mazmanian SK. Host-bacterial symbiosis in health and disease. Adv Immunol. 2010; 107:243-74. https://doi.org/10.1016/B978-0-12-381300-8.00008$\underline{3}$ PMID:21034976

7. Cani PD, Knauf C. How gut microbes talk to organs: The role of endocrine and nervous routes. Mol Metab. 2016; 5:743-52. https://doi.org/10.1016/i.molmet.2016.05.011 PMID:27617197

8. Dinan TG, Cryan JF. The Microbiome-Gut-Brain Axis in Health and Disease. Gastroenterol Clin North Am. 2017; 46:77-89. https://doi.org/10.1016/i.gtc.2016.09.007 PMID:28164854

9. Galland L. The gut microbiome and the brain. J Med Food. 2014; 17:1261-72. 
https://doi.org/10.1089/imf.2014.7000

PMID:25402818

10. Bonaz B, Bazin T, Pellissier S. The Vagus Nerve at the Interface of the Microbiota-Gut-Brain Axis. Front Neurosci. 2018; 12:49.

https://doi.org/10.3389/fnins.2018.00049 PMID:29467611

11. Fröhlich EE, Farzi A, Mayerhofer R, Reichmann F, Jačan A, Wagner B, Zinser E, Bordag N, Magnes C, Fröhlich E, Kashofer K, Gorkiewicz G, Holzer P. Cognitive impairment by antibiotic-induced gut dysbiosis: Analysis of gut microbiota-brain communication. Brain Behav Immun. 2016; 56:140-55.

https://doi.org/10.1016/j.bbi.2016.02.020 PMID:26923630

12. Leclercq S, Mian FM, Stanisz AM, Bindels LB, Cambier $\mathrm{E}$, Ben-Amram H, Koren O, Forsythe P, Bienenstock J. Low-dose penicillin in early life induces long-term changes in murine gut microbiota, brain cytokines and behavior. Nat Commun. 2017; 8:15062.

https://doi.org/10.1038/ncomms15062 PMID:28375200

13. Rieder R, Wisniewski PJ, Alderman BL, Campbell SC. Microbes and mental health: A review. Brain Behav Immun. 2017; 66:9-17.

https://doi.org/10.1016/i.bbi.2017.01.016 PMID:28131791

14. Sampson TR, Mazmanian SK. Control of brain development, function, and behavior by the microbiome. Cell Host Microbe. 2015; 17:565-76.

https://doi.org/10.1016/j.chom.2015.04.011 PMID:25974299

15. Bohórquez DV, Shahid RA, Erdmann A, Kreger AM, Wang $Y$, Calakos N, Wang $F$, Liddle RA. Neuroepithelial circuit formed by innervation of sensory enteroendocrine cells. J Clin Invest. 2015; 125:782-6.

https://doi.org/10.1172/JCI78361

PMID:25555217

16. Mayer EA, Tillisch K, Gupta A. Gut/brain axis and the microbiota. J Clin Invest. 2015; 125:926-38.

https://doi.org/10.1172/JCI76304

PMID:25689247

17. Yano JM, Yu K, Donaldson GP, Shastri GG, Ann P, Ma L, Nagler CR, Ismagilov RF, Mazmanian SK, Hsiao EY. Indigenous bacteria from the gut microbiota regulate host serotonin biosynthesis. Cell. 2015; 161:264-76. https://doi.org/10.1016/i.cell.2015.02.047 PMID:25860609

18. Harach T, Marungruang N, Duthilleul N, Cheatham V, Mc Coy KD, Frisoni G, Neher JJ, Fåk F, Jucker M, Lasser $\mathrm{T}$, Bolmont T. Reduction of Abeta amyloid pathology in APPPS1 transgenic mice in the absence of gut microbiota. Sci Rep. 2017; 7:41802.

https://doi.org/10.1038/srep41802

PMID:28176819

19. Wang T, Hu X, Liang S, Li W, Wu X, Wang L, Jin F. Lactobacillus fermentum NS9 restores the antibiotic induced physiological and psychological abnormalities in rats. Benef Microbes. 2015; 6:707-17. https://doi.org/10.3920/BM2014.0177 PMID:25869281

20. Ulluwishewa D, Anderson RC, McNabb WC, Moughan PJ, Wells JM, Roy NC. Regulation of tight junction permeability by intestinal bacteria and dietary components. J Nutr. 2011; 141:769-76.

https://doi.org/10.3945/in.110.135657 PMID:21430248

21. Bäuerl C, Collado MC, Diaz Cuevas A, Viña J, Pérez Martínez G. Shifts in gut microbiota composition in an APP/PSS1 transgenic mouse model of Alzheimer's disease during lifespan. Lett Appl Microbiol. 2018; 66:464-71.

https://doi.org/10.1111/lam.12882

PMID:29575030

22. Wu SC, Cao ZS, Chang KM, Juang JL. Intestinal microbial dysbiosis aggravates the progression of Alzheimer's disease in Drosophila. Nat Commun. 2017; 8:24.

https://doi.org/10.1038/s41467-017-00040-6

PMID:28634323

23. Hou M, Xu G, Ran M, Luo W, Wang H. APOE- $\varepsilon 4$ Carrier Status and Gut Microbiota Dysbiosis in Patients With Alzheimer Disease. Front Neurosci. 2021; 15:619051.

https://doi.org/10.3389/fnins.2021.619051 PMID:33732104

24. Li B, He Y, Ma J, Huang P, Du J, Cao L, Wang Y, Xiao Q, Tang $\mathrm{H}$, Chen $\mathrm{S}$. Mild cognitive impairment has similar alterations as Alzheimer's disease in gut microbiota. Alzheimers Dement. 2019; 15:1357-66.

https://doi.org/10.1016/j.jalz.2019.07.002 PMID:31434623

25. Liu P, Wu L, Peng G, Han Y, Tang R, Ge J, Zhang L, Jia L, Yue S, Zhou K, Li L, Luo B, Wang B. Altered microbiomes distinguish Alzheimer's disease from amnestic mild cognitive impairment and health in a Chinese cohort. Brain Behav Immun. 2019; 80:633-43. https://doi.org/10.1016/j.bbi.2019.05.008 PMID:31063846

26. Vogt NM, Kerby RL, Dill-McFarland KA, Harding SJ, Merluzzi AP, Johnson SC, Carlsson CM, Asthana S, Zetterberg H, Blennow K, Bendlin BB, Rey FE. Gut microbiome alterations in Alzheimer's disease. Sci Rep. 2017; 7:13537. 
https://doi.org/10.1038/s41598-017-13601-y PMID:29051531

27. Zhuang ZQ, Shen LL, Li WW, Fu X, Zeng F, Gui L, Lü Y, Cai M, Zhu C, Tan YL, Zheng P, Li HY, Zhu J, et al. Gut Microbiota is Altered in Patients with Alzheimer's Disease. J Alzheimers Dis. 2018; 63:1337-46.

https://doi.org/10.3233/JAD-180176 PMID:29758946

28. Nagpal R, Neth BJ, Wang S, Craft S, Yadav H. Modified Mediterranean-ketogenic diet modulates gut microbiome and short-chain fatty acids in association with Alzheimer's disease markers in subjects with mild cognitive impairment. EBioMedicine. 2019; 47:529-42.

https://doi.org/10.1016/i.ebiom.2019.08.032 PMID: 31477562

29. Zhou Y, Wang Y, Quan M, Zhao H, Jia J. Gut Microbiota Changes and Their Correlation with Cognitive and Neuropsychiatric Symptoms in Alzheimer's Disease. J Alzheimers Dis. 2021; 81:583-95. https://doi.org/10.3233/JAD-201497 PMID:33814442

30. Den H, Dong X, Chen M, Zou Z. Efficacy of probiotics on cognition, and biomarkers of inflammation and oxidative stress in adults with Alzheimer's disease or mild cognitive impairment - a meta-analysis of randomized controlled trials. Aging (Albany NY). 2020; 12:4010-39. https://doi.org/10.18632/aging.102810 PMID:32062613

31. Krüger JF, Hillesheim E, Pereira ACS, Camargo CQ, Rabito El. Probiotics for dementia: a systematic review and meta-analysis of randomized controlled trials. Nutr Rev. 2021; 79:160-70. https://doi.org/10.1093/nutrit/nuaa037 PMID: 32556236

32. Heshmati J, Farsi F, Yosaee S, Razavi M, Rezaeinejad M, Karimie E, Sepidarkish M. The Effects of Probiotics or Synbiotics Supplementation in Women with Polycystic Ovarian Syndrome: a Systematic Review and Meta-Analysis of Randomized Clinical Trials. Probiotics Antimicrob Proteins. 2019; 11:1236-47. https://doi.org/10.1007/s12602-018-9493-9 PMID:30547393

33. Huang $\mathrm{R}$, Wang $\mathrm{K}$, Hu J. Effect of Probiotics on Depression: A Systematic Review and Meta-Analysis of Randomized Controlled Trials. Nutrients. 2016; 8:483. https://doi.org/10.3390/nu8080483 PMID:27509521

34. Page MJ, McKenzie JE, Bossuyt PM, Boutron I, Hoffmann TC, Mulrow CD, Shamseer L, Tetzlaff JM, Akl EA, Brennan SE, Chou R, Glanville J, Grimshaw JM, et al. The PRISMA 2020 statement: An updated guideline for reporting systematic reviews. Int J Surg. 2021; 88:105906.

https://doi.org/10.1016/j.ijsu.2021.105906

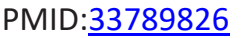

35. Liu P, Jia XZ, Chen Y, Yu Y, Zhang K, Lin YJ, Wang BH, Peng GP. Gut microbiota interacts with intrinsic brain activity of patients with amnestic mild cognitive impairment. CNS Neurosci Ther. 2021; 27:163-73. https://doi.org/10.1111/cns.13451 PMID:32929861

36. Kim SY, Park JE, Lee YJ, Seo HJ, Sheen SS, Hahn S, Jang $\mathrm{BH}$, Son HJ. Testing a tool for assessing the risk of bias for nonrandomized studies showed moderate reliability and promising validity. J Clin Epidemiol. 2013; 66:408-14.

https://doi.org/10.1016/i.jclinepi.2012.09.016 PMID:23337781

37. Hozo SP, Djulbegovic B, Hozo I. Estimating the mean and variance from the median, range, and the size of a sample. BMC Med Res Methodol. 2005; 5:13. https://doi.org/10.1186/1471-2288-5-13 PMID: 15840177

38. Noma H, Gosho M, Ishii R, Oba K, Furukawa TA. Outlier detection and influence diagnostics in network meta-analysis. Res Synth Methods. 2020; 11:891-902.

https://doi.org/10.1002/jrsm.1455 PMID:32921002

39. Viechtbauer W, Cheung MW. Outlier and influence diagnostics for meta-analysis. Res Synth Methods. 2010; 1:112-25. https://doi.org/10.1002/jrsm.11 PMID:26061377

40. Begg CB, Mazumdar M. Operating characteristics of a rank correlation test for publication bias. Biometrics. 1994; 50:1088-101.

https://doi.org/10.2307/2533446

PMID:7786990

41. Egger M, Davey Smith G, Schneider M, Minder C. Bias in meta-analysis detected by a simple, graphical test. BMJ. 1997; 315:629-34. https://doi.org/10.1136/bmj.315.7109.629 PMID:9310563

42. Ling Z, Zhu M, Yan X, Cheng Y, Shao L, Liu X, Jiang R, Wu S. Structural and Functional Dysbiosis of Fecal Microbiota in Chinese Patients With Alzheimer's Disease. Front Cell Dev Biol. 2021; 8:634069.

https://doi.org/10.3389/fcell.2020.634069 PMID:33614635

43. Xi J, Ding D, Zhu H, Wang R, Su F, Wu W, Xiao Z, Liang X, Zhao Q, Hong Z, Fu H, Xiao Q. Disturbed microbial 
ecology in Alzheimer's disease: evidence from the gut microbiota and fecal metabolome. BMC Microbiol. 2021; 21:226.

https://doi.org/10.1186/s12866-021-02286-z PMID:34384375

44. Cattaneo A, Cattane N, Galluzzi S, Provasi S, Lopizzo N, Festari C, Ferrari C, Guerra UP, Paghera B, Muscio C, Bianchetti A, Volta GD, Turla M, et al, and INDIAFBP Group. Association of brain amyloidosis with proinflammatory gut bacterial taxa and peripheral inflammation markers in cognitively impaired elderly. Neurobiol Aging. 2017; 49:60-8.

https://doi.org/10.1016/j.neurobiolaging.2016.08.019 PMID:27776263

45. Sheng C, Lin L, Lin H, Wang X, Han Y, Liu SL. Altered Gut Microbiota in Adults with Subjective Cognitive Decline: The SILCODE Study. J Alzheimers Dis. 2021; 82:513-26.

https://doi.org/10.3233/JAD-210259

PMID:34024839

46. Zhang $X$, Wang $Y$, Liu $W$, Wang $T$, Wang $L$, Hao L, Ju $M$, Xiao R. Diet quality, gut microbiota, and microRNAs associated with mild cognitive impairment in middle-aged and elderly Chinese population. Am J Clin Nutr. 2021; 114:429-40.

https://doi.org/10.1093/ajcn/nqab078 PMID:33871591

47. Haran JP, Bhattarai SK, Foley SE, Dutta P, Ward DV, Bucci V, McCormick BA. Alzheimer's Disease Microbiome Is Associated with Dysregulation of the Anti-Inflammatory P-Glycoprotein Pathway. mBio. 2019; 10:e00632-19.

https://doi.org/10.1128/mBio.00632-19 PMID:31064831

48. Petrov VA, Saltykova IV, Zhukova IA, Alifirova VM, Zhukova NG, Dorofeeva YB, Tyakht AV, Kovarsky BA, Alekseev DG, Kostryukova ES, Mironova YS, Izhboldina OP, Nikitina MA, et al. Analysis of Gut Microbiota in Patients with Parkinson's Disease. Bull Exp Biol Med. 2017; 162:734-7. https://doi.org/10.1007/s10517-017-3700-7 PMID:28429209

49. Zhuang $X$, Xiong L, Li L, Li M, Chen M. Alterations of gut microbiota in patients with irritable bowel syndrome: A systematic review and meta-analysis. J Gastroenterol Hepatol. 2017; 32:28-38.

https://doi.org/10.1111/igh.13471 PMID:27300149

50. Zhao Y, Lukiw WJ. Bacteroidetes Neurotoxins and Inflammatory Neurodegeneration. Mol Neurobiol. 2018; 55:9100-7. https://doi.org/10.1007/s12035-018-1015-y PMID:29637444
51. Hossain S, Beydoun MA, Kuczmarski MF, Tajuddin S, Evans MK, Zonderman AB. The Interplay of Diet Quality and Alzheimer's Disease Genetic Risk Score in Relation to Cognitive Performance Among Urban African Americans. Nutrients. 2019; 11:2181.

https://doi.org/10.3390/nu11092181 PMID:31514322

52. Jeong MY, Jang HM, Kim DH. High-fat diet causes psychiatric disorders in mice by increasing Proteobacteria population. Neurosci Lett. 2019; 698:51-7. https://doi.org/10.1016/i.neulet.2019.01.006 PMID:30615977

53. Kumar H, Lund R, Laiho A, Lundelin K, Ley RE, Isolauri $\mathrm{E}$, Salminen S. Gut microbiota as an epigenetic regulator: pilot study based on whole-genome methylation analysis. mBio. 2014; 5:e02113-4.

https://doi.org/10.1128/mBio.02113-14 PMID:25516615

54. Welcome MO. Gut Microbiota Disorder, Gut Epithelial and Blood-Brain Barrier Dysfunctions in Etiopathogenesis of Dementia: Molecular Mechanisms and Signaling Pathways. Neuromolecular Med. 2019; 21:205-26. https://doi.org/10.1007/s12017-019-08547-5 PMID: $\underline{3115795}$

55. Allin KH, Tremaroli $V$, Caesar $R$, Jensen $B A H$, Damgaard MTF, Bahl MI, Licht TR, Hansen TH, Nielsen T, Dantoft TM, Linneberg A, Jørgensen T, Vestergaard $\mathrm{H}$, et al, and IMI-DIRECT consortium. Aberrant intestinal microbiota in individuals with prediabetes. Diabetologia. 2018; 61:810-20.

https://doi.org/10.1007/s00125-018-4550-1 PMID:29379988

56. Schwiertz A, Taras D, Schäfer K, Beijer S, Bos NA, Donus C, Hardt PD. Microbiota and SCFA in lean and overweight healthy subjects. Obesity (Silver Spring). 2010; 18:190-5. https://doi.org/10.1038/oby.2009.167 PMID: 19498350

57. Willette AA, Bendlin BB, Starks EJ, Birdsill AC, Johnson SC, Christian BT, Okonkwo OC, La Rue A, Hermann BP, Koscik RL, Jonaitis EM, Sager MA, Asthana S. Association of Insulin Resistance With Cerebral Glucose Uptake in Late Middle-Aged Adults at Risk for Alzheimer Disease. JAMA Neurol. 2015; 72:1013-20. https://doi.org/10.1001/jamaneurol.2015.0613 PMID:26214150

58. Willette AA, Johnson SC, Birdsill AC, Sager MA, Christian B, Baker LD, Craft S, Oh J, Statz E, Hermann $B P$, Jonaitis EM, Koscik RL, La Rue A, et al. Insulin resistance predicts brain amyloid deposition in late middle-aged adults. Alzheimers Dement. 2015; 11:504-10.e1. 
https://doi.org/10.1016/i.jalz.2014.03.011 PMID:25043908

59. Bhat MI, Kapila R. Dietary metabolites derived from gut microbiota: critical modulators of epigenetic changes in mammals. Nutr Rev. 2017; 75:374-89.

https://doi.org/10.1093/nutrit/nux001 PMID:28444216

60. Fung TC, Olson CA, Hsiao EY. Interactions between the microbiota, immune and nervous systems in health and disease. Nat Neurosci. 2017; 20:145-55. https://doi.org/10.1038/nn.4476 PMID:28092661

61. Chyan YJ, Poeggeler B, Omar RA, Chain DG, Frangione B, Ghiso J, Pappolla MA. Potent neuroprotective properties against the Alzheimer beta-amyloid by an endogenous melatonin-related indole structure, indole-3-propionic acid. J Biol Chem. 1999; 274:21937-42.

https://doi.org/10.1074/jbc.274.31.21937 PMID:10419516

62. Chang PV, Hao L, Offermanns S, Medzhitov R. The microbial metabolite butyrate regulates intestinal macrophage function via histone deacetylase inhibition. Proc Natl Acad Sci U S A. 2014; 111:2247-52. https://doi.org/10.1073/pnas.1322269111 PMID:24390544

63. Wong JM, de Souza R, Kendall CW, Emam A, Jenkins DJ. Colonic health: fermentation and short chain fatty acids. J Clin Gastroenterol. 2006; 40:235-43. https://doi.org/10.1097/00004836-200603000-00015 PMID:16633129

64. Silva YP, Bernardi A, Frozza RL. The Role of Short-Chain Fatty Acids From Gut Microbiota in Gut-Brain Communication. Front Endocrinol (Lausanne). 2020; 11:25. https://doi.org/10.3389/fendo.2020.00025 PMID: 32082260

65. Barrett E, Ross RP, O'Toole PW, Fitzgerald GF, Stanton C. Y-Aminobutyric acid production by culturable bacteria from the human intestine. J Appl Microbiol. 2012; 113:411-7. https://doi.org/10.1111/j.1365-2672.2012.05344.x PMID:22612585

66. Koh A, De Vadder F, Kovatcheva-Datchary P, Bäckhed F. From Dietary Fiber to Host Physiology: Short-Chain Fatty Acids as Key Bacterial Metabolites. Cell. 2016; 165:1332-45.

https://doi.org/10.1016/i.cell.2016.05.041

PMID:27259147
67. Underwood MA, German JB, Lebrilla CB, Mills DA. Bifidobacterium longum subspecies infantis: champion colonizer of the infant gut. Pediatr Res. 2015; 77:229-35.

https://doi.org/10.1038/pr.2014.156

PMID:25303277

68. Mancuso C, Santangelo R. Alzheimer's disease and gut microbiota modifications: The long way between preclinical studies and clinical evidence. Pharmacol Res. 2018; 129:329-36.

https://doi.org/10.1016/j.phrs.2017.12.009 PMID:29233677

69. Bonfili L, Cecarini V, Berardi S, Scarpona S, Suchodolski JS, Nasuti C, Fiorini D, Boarelli MC, Rossi G, Eleuteri AM. Microbiota modulation counteracts Alzheimer's disease progression influencing neuronal proteolysis and gut hormones plasma levels. Sci Rep. 2017; 7:2426.

https://doi.org/10.1038/s41598-017-02587-2

PMID:28546539

70. Hsiao EY, McBride SW, Hsien S, Sharon G, Hyde ER, McCue T, Codelli JA, Chow J, Reisman SE, Petrosino JF, Patterson PH, Mazmanian SK. Microbiota modulate behavioral and physiological abnormalities associated with neurodevelopmental disorders. Cell. 2013; 155:1451-63.

https://doi.org/10.1016/i.cell.2013.11.024

PMID:24315484

71. Rhee KJ, Wu S, Wu X, Huso DL, Karim B, Franco AA, Rabizadeh S, Golub JE, Mathews LE, Shin J, Sartor RB, Golenbock D, Hamad AR, et al. Induction of persistent colitis by a human commensal, enterotoxigenic Bacteroides fragilis, in wild-type C57BL/6 mice. Infect Immun. 2009; 77:1708-18.

https://doi.org/10.1128/IAI.00814-08

PMID:19188353

72. Wu S, Rhee KJ, Albesiano E, Rabizadeh S, Wu X, Yen $H R$, Huso DL, Brancati FL, Wick E, McAllister F, Housseau F, Pardoll DM, Sears CL. A human colonic commensal promotes colon tumorigenesis via activation of $\mathrm{T}$ helper type $17 \mathrm{~T}$ cell responses. Nat Med. 2009; 15:1016-22. https://doi.org/10.1038/nm.2015 PMID:19701202 


\section{SUPPLEMENTARY MATERIALS}

\section{Supplementary Tables}

Supplementary Table 1. Bias of the 11 studies included in this meta-analysis based on RoBANS.

\begin{tabular}{|c|c|c|c|c|c|c|}
\hline Study & $\begin{array}{c}\text { The selection } \\
\text { of participants }\end{array}$ & $\begin{array}{l}\text { Confounding } \\
\text { variables }\end{array}$ & $\begin{array}{l}\text { Measurement } \\
\text { of exposure }\end{array}$ & $\begin{array}{l}\text { Blinding of outcome } \\
\text { assessments }\end{array}$ & $\begin{array}{c}\text { Incomplete } \\
\text { outcome data }\end{array}$ & $\begin{array}{c}\text { Selective } \\
\text { outcome } \\
\text { reporting }\end{array}$ \\
\hline Vogt et al. (2017) & Low risk & High risk & Low risk & Low risk & Low risk & Low risk \\
\hline Zhuang et al. (2018) & Low risk & High risk & Low risk & Low risk & Low risk & Low risk \\
\hline Haran et al. (2019) & Low risk & High risk & Low risk & Low risk & Low risk & Low risk \\
\hline Li et al. (2019) & Low risk & High risk & Low risk & Low risk & Low risk & Low risk \\
\hline Liu et al. (2019) & Low risk & High risk & Low risk & Low risk & Low risk & Low risk \\
\hline Nagpal et al. (2019) & Low risk & High risk & Low risk & Low risk & Low risk & Low risk \\
\hline Hou et al. (2021) & Low risk & Low risk & Low risk & Low risk & Low risk & Low risk \\
\hline Liu et al. (2021) & Low risk & High risk & Low risk & Low risk & Low risk & Low risk \\
\hline Sheng et al. (2021) & Low risk & High risk & Low risk & Low risk & Low risk & Low risk \\
\hline Zhang et al. (2021) & Low risk & High risk & Low risk & Low risk & Low risk & Low risk \\
\hline Zhou et al. (2021) & Low risk & High risk & Low risk & Low risk & Low risk & Low risk \\
\hline
\end{tabular}

Abbreviation: RoBANS: Risk of Bias Assessment tool for Non-randomized Studies.

Supplementary Table 2. Publication bias assessments.

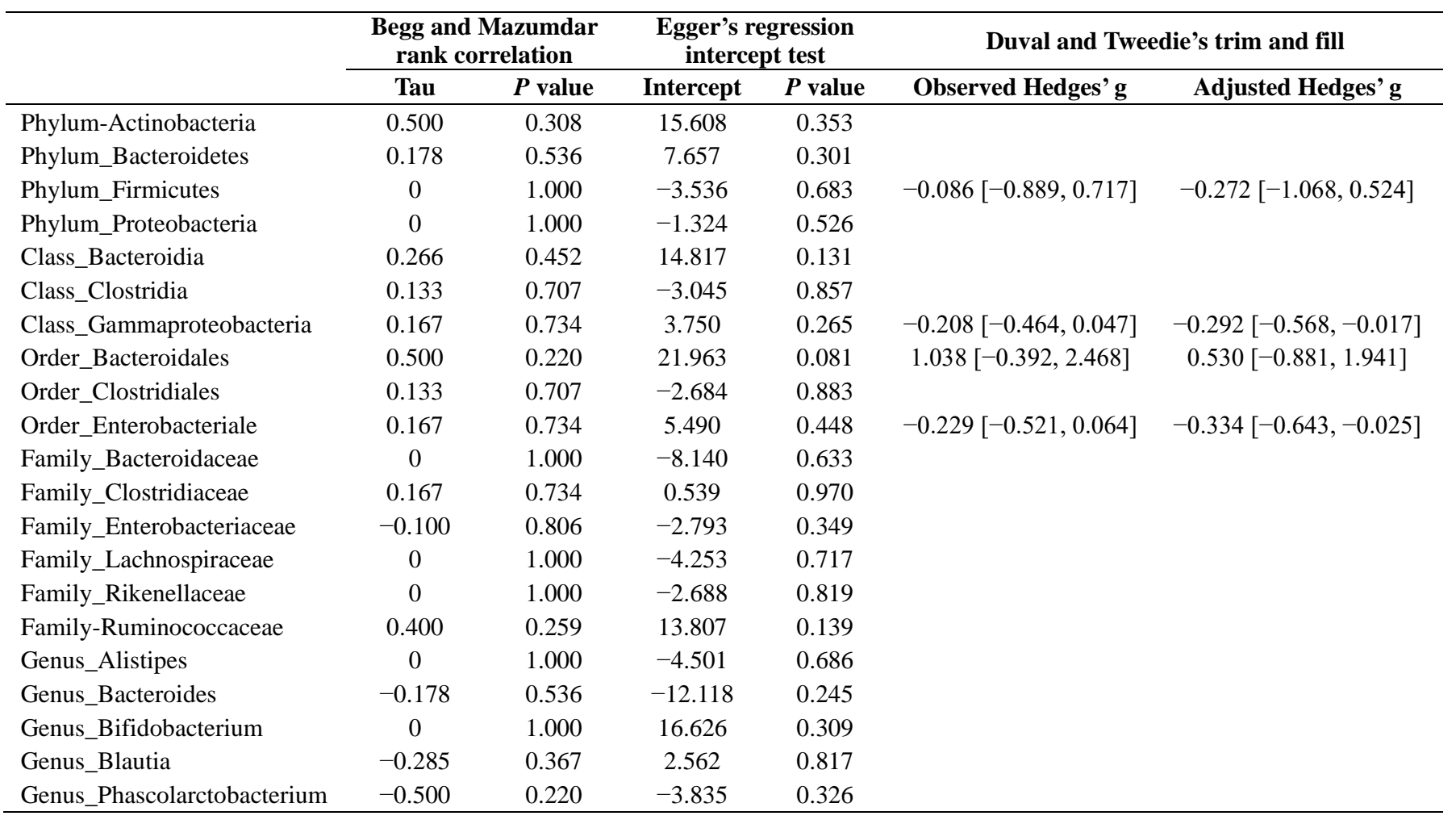

Note: the observed and adjusted effects sizes were reported only when missing studies were found and corrected by Duval and Tweedie's trim and fill. The Hedges' $g$ was presented as overall effect size [lower limit, upper limit]. 